\title{
A review on advances in methods for modification of paper supports for use in point-of-care testing
}

\author{
Rui Hua Tang ${ }^{1,2,3,4} \cdot \mathrm{Li} \mathrm{Na} \mathrm{Liu}^{1,2} \cdot$ Su Feng Zhang ${ }^{5,6} \cdot$ Xiao Cong He ${ }^{3,4} \cdot$ Xiu Jun $\mathrm{Li}^{7} \cdot$ Feng $\mathrm{Xu}^{3,4} \cdot$ Yong Hao $\mathrm{Ni}^{1,8}$. \\ Fei $\mathrm{Li}^{3,4}$
}

Received: 15 March 2019 / Accepted: 17 June 2019 / Published online: 9 July 2019

(C) Springer-Verlag GmbH Austria, part of Springer Nature 2019

\begin{abstract}
Paper is a widely used support for use in devices for point-of-care testing (POCT) in clinical diagnosis, food safety monitoring and environmental pollution. Paper is inexpensive, biocompatible, biodegradable and allows a sample fluid to flow by capillary force. Numerous method have been developed recently for chemical modification of papers in order to introduce different functionalities. This review (with 148 refs.) summarizes the recent progress in paper-based POCT devices. The introduction summarizes the state of the art of paper-based POCT devices and the physicochemical properties of existing unmodified materials (including cellulose, cellulose-based composites, cotton fibers, glass fibers, nitrocellulose, thread). Methods for paper modification for sample pretreatment are summarized next, with subsections on sample storage and collection, sample separation, nucleic acid extraction and sample preconcentration. Another main section covers approaches for paper modification for improving POCTs, with subsections on assays for proteins, nucleic acids, drugs, ion and organic molecules. The advantages and disadvantages of these approaches are compared. Several tables are presented that summarize the various modification techniques. A concluding section summarizes the current status, addresses challenges and gives an outlook on future perspectives of POCTs.
\end{abstract}

Keywords Paper-based POCT device $\cdot$ Nanomaterials $\cdot$ Lateral flow assays $\cdot$ Sample pretreatment $\cdot$ Nanolabels

\section{Introduction}

Point-of-care testing (POCT), an affordable, sensitive, specific, user-friendly, rapid and robust, equipment-free, and deliverable (ASSURED) technology [1], has utilized outside of clinical laboratory near the patient or bedside [2] and further found widespread applications in biomedical fields, including disease diagnosis, food safety monitoring

Yong Hao Ni

yonghao@unb.ca

Fei Li

feili@mail.xjtu.edu.cn

1 College of Bioresources Chemical and Materials Engineering, Shaanxi University of Science \& Technology, Xi'an 710021, People's Republic of China

2 National Demonstration Center for Experimental Light Chemistry Engineering Education, Shaanxi University of Science \& Technology, Xi'an 710021, People's Republic of China

3 The Key Laboratory of Biomedical Information Engineering of Ministry of Education, School of Life Science and Technology, Xi' an Jiaotong University, Xi'an 710049, People's Republic of China and environmental pollution detection [3-5]. Paper, as a ubiquitous substance in daily life, has attracted increasing attention as a powerful microfluidic platform for POCT due to its low cost, biocompatibility, portability, biodegradability and capability to drive fluid flow by capillary force [6-9]. For detection of various targets using the paper-based POCT devices, development of different types of papers is needed.

4 Bioinspired Engineering and Biomechanics Center (BEBC), Xi'an Jiaotong University, Xi'an 710049, People's Republic of China

5 Key laboratory of Paper Based Functional Materials of China National Light Industry, Shaanxi University of Science \& Technology, Xi'an 710021, People's Republic of China

6 Shaanxi Province Key Laboratory of Papermaking Technology and Specialty Paper Development, Shaanxi University of Science \& Technology, Xi'an 710021, People's Republic of China

7 Department of Chemistry, University of Texas at El Paso, 500 West University Ave, El Paso, TX 79968, USA

8 Limerick Pulp and Paper Centre, University of New Brunswick, Fredericton, New Brunswick E3B 5A3, Canada 
Normally, samples contain multiple components and need pretreatment procedure to purify target before detection. Different types of papers have been directly used to fabricate paper-based devices for sample pretreatment and detection [10-16]. For instance, blood separation membranes with highly asymmetric pore structures was used to separate plasma from whole blood [17]. Fusion 5 membranes from Whatman ${ }^{\circledR}$ was used for nucleic acid extraction [18] based on the high affinity between the positively charged glass fibers of the Fusion 5 and negatively charged DNA. Nitrocellulose (NC) membranes, adsorption paper and glass fibers as the main materials were used to fabricate lateral flow assays (LFAs) test strips based on their physicochemical features (e.g., noncovalent interactions/electrostatic adsorption between the paper and chemical molecules) for detections of proteins [19], nucleic acids [15] and ions/chemical molecules [20]. However, these papers have limitations which restrict their further POCT applications [21]. For example, the limited range of sample volumes on one layer of blood separation membrane (10 $\mu \mathrm{L}$ [22] 100 $\mu \mathrm{L}$ [23]) cannot meet the requirements of the relatively low detection sensitivity of several assays [17]. The efficiency of Fusion 5 in extracting nucleic acid is low because of the nonspecific absorbance of cell debris and interferents (e.g., hemoglobin), which affects the extraction purity and thus the analytical result [21]. In addition, the detection sensitivity and specificity of LFAs are still poor because the biological molecules (e.g., DNA, antibodies and antigens) are immobilized on $\mathrm{NC}$ membranes based on the simple physical adsorption of chemical reagents, which causes the nonspecific adsorption issue [24, 25]. To improve the performance of the paper-based devices and overcome these challenges, modification approaches to prepare papers with more functions for POCT applications are needed.

With the recent advances in paper materials, micro/ nanotechnologies and nanomaterials, various modification approaches have been developed and used to improve the performance of paper-based POCT devices (Fig. 1). For example, a chitosan-based modification technology was utilized to modify Fusion 5 paper to improve the adsorption performance of DNA on the paper [12]. Paper functionalized with zinc oxide nanorods was used to preconcentrate myoglobin with enhanced performance compared to that of the unmodified paper [13]. A chemoenzymatic modification technology was developed to prepare paper-based fluorogenic esterase biosensors [26]. A wax-based technology was applied to modify hydrophobic patterns and hydrophobic barriers on paper using a wax printer [27] and a pen-writing approach [28]. Different nanomaterials, such as quantum dots (QDs) [29-33], gold nanoparticles (AuNPs) [24, 34-46], AuNFs ${ }^{\mathrm{MBA} @ A g ~[47] ~}$ $\mathrm{Cu}-\mathrm{Pd} / \mathrm{rGO}$ nanoparticles [48], upconverting fluorescent nanocrystals [49], metal-organic framework [50], fluorescent nanoparticles [51], gold nanocage [52], gold nanorods [53], multi-walled carbon nanotubes and graphene oxide [54] and polymer nanoparticles [55], have also been used as reading signal in paper-based POCT devices. The functional papers prepared by these advanced modification approaches significantly extend the application potential of paper as the substrate of POCT devices.

Thus, considering the paper modification approaches are critical for improving the performance of paper-based POCT devices, it is urgently needed for a review to summarize and compare the existing modification approaches of paper. Previous reviews mainly focus on the working principles [56], fluid flow theory [57], inkjet-printed fabrication technology [58] and fabrication materials and methods [59] of paperbased POCT devices. So in this review, we first summarize the existing papers and their physicochemical properties. Then we introduce the paper modification approaches for sample pretreatment and sample detection, which are the two major steps of paper-based POCT, and then highlight modification processes for fabricating paper-based devices. The advantages and disadvantages of paper modification approaches are also compared. Finally, we discuss the challenges and future perspectives of paper modification technology for POCT.

\section{Existing unmodified papers for paper-based POCT and their physicochemical properties}

Sample analysis process normally includes two steps: sample pretreatment (e.g., sample collection and storage, sample separation, nucleic acid extraction and sample pre-concentration) and sample detection (e.g., nucleic acid detection, protein detection and ion/chemical molecule detection). Conventional methods for sample pretreatment and sample detection, such as centrifuge, thermocycling instrument, filter device, sodium dodecyl sulfate polyacrylamide gel electrophoresis (SDSPAGE), usually require large, expensive, nonportable and complex equipment. And professional and skilled workers are needed to purify samples and retain targets before downstream analysis. Hence, portable, cheap and easy-to-use devices are urgently needed, especially for the resource-limited situations. Since Whiteside's group first used paper to fabricate paper-based microfluidic devices [60], various types of papers with biomolecule adsorption capability and porous structure have been invented and used to prepare low-cost, simple and portable paper-based microfluidic devices, especially for sample pretreatment and sample detection in the POCT field.

\section{Physicochemical properties of existing unmodified papers}

The physicochemical properties of paper are the key factors affecting the performance of paper-based devices [61, 62]. For example, the pore size, specific surface area and 


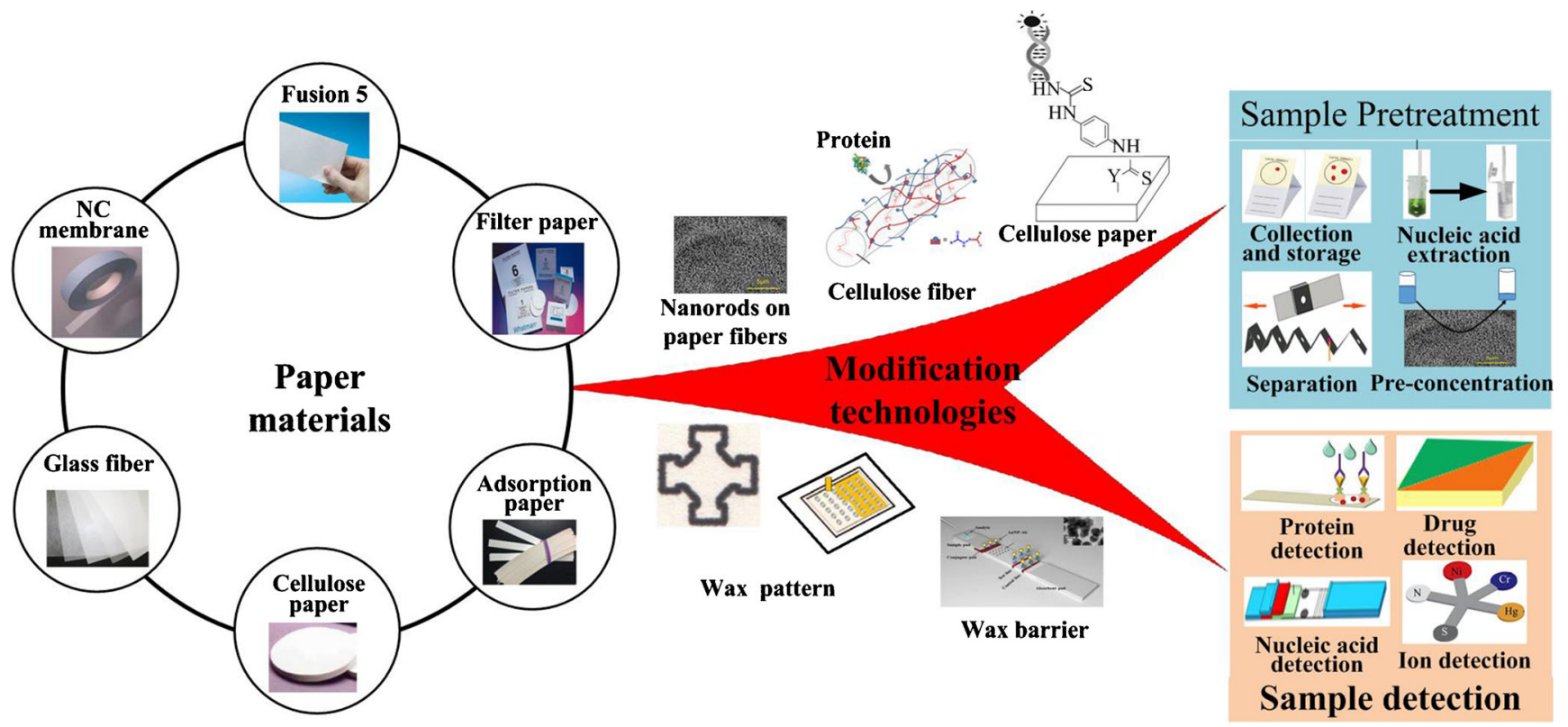

Fig. 1 Existing paper modification approaches for paper-based POCT. Different paper materials, including Fusion 5, filter paper, chromatography paper, cellulose paper, Whatman ${ }^{\circledR}$ No.1 filter paper and NC

hydrophobicity/hydrophilicity of paper affect the capillary forces [63], adsorption ability and flow rate of the paper $[64,65]$. Chemical groups on paper surface (e.g., hydroxyl and carboxyl groups) can help immobilize chemical reagents on paper to achieve chemical reactions [66]. Thus, to provide a reference and guidance for choosing proper materials for preparation of paper-based devices, various types of the papers (including cellulose, cotton fiber, glass fiber, nitrocellulose membrane, thread) and their physicochemical properties are first introduced. A material selection diagram according to the equilibrium time and adsorption capacity of the paper material is shown in Fig. 2.

Cellulose Cellulose usually with diameter of 30-40 nm (up to $\sim 100 \mathrm{~nm}$ ) and specific surface area of $1.4 \mathrm{~m}^{2} \cdot \mathrm{g}^{-1}$ is produced by plants or bacteria. Cellulose contains hydroxyl groups on its surface and has the properties of hydrophilicity, easy usability, high porosity, high mechanical strength and degradability [86, 87]. Cellulose can be made into cellophane films and has a porous structure to provide abundant binding sites for adsorption of biomolecules through functionalization [88]. Bacterial cellulose (BC), which is produced by bacteria and has natural biosorbent, renewable, biodegradable and biocompatible properties has emerged as a new type of cellulose paper for preparing paper-based POCT devices [89]. And the $\mathrm{BC}$ fiber has a size of $100 \mathrm{~nm}$ and high porosity of $92 \%$ [90-92]. The amino groups on the BC surfaces can be used to remove residues and adsorb biomolecules, including proteins membrane, have been modified with various reagents for paper-based sample pretreatment and paper-based detection

(e.g., bovine serum albumen, BSA) and heavy metals (e.g., $\mathrm{Pb}^{2+}, \mathrm{Cd}^{2+}$ and $\mathrm{Ni}^{2+}$ ) [67]. The porous structure of $\mathrm{BC}$ can adsorb biomolecules based on chemical bonds or physical adsorption. BC can be used as a substrate in paper-based POCT devices for sample pretreatment and sample detection.

Cellulose-based composite materials Cellulose-based composite papers are composed of hybrids of cellulose with various materials, such as Eichhornia crassipes/chitosan, graphene oxide, maleic and phthalic anhydride [68-70, 93, 94]. The physicochemical properties of these composite materials such as surface functional groups, specific surface area and hydrophilicity, are better than those of the pure cellulose. For example, E. crassipes/chitosan composite materials have hydroxyl groups and $-\mathrm{CH}$ groups on their surface and with specific surface areas ranging from $132.95 \mathrm{~m}^{2} \cdot \mathrm{g}^{-1}$ to $172.49 \mathrm{~m}^{2} \cdot \mathrm{g}^{-1}$ and adsorption abilities of up to $0.606 \mathrm{mg}^{-\mathrm{g}^{-1}}$ at an equilibrium time of $180 \mathrm{~min}$ [93]. Graphene oxide/sawdust composites have both the advantages of graphene (e.g., abundant oxygen-containing groups) and cellulose (e.g., nontoxic, biodegradable, renewable and modifiable) and contain mainly $\mathrm{C}$ $\mathrm{C}$ groups on their surface. Graphene oxide/sawdust composites have a specific surface area ranging from $124.92 \mathrm{~m}^{2} \cdot \mathrm{g}^{-1}$ to $78.13 \mathrm{~m}^{2} \cdot \mathrm{g}^{-1}$ and an adsorption capacity up to $158.98 \mathrm{mg} \cdot \mathrm{g}^{-1}$ at $30 \mathrm{~min}$ [68]. Graphene oxide/microcrystalline cellulose aerogels, with the advantages of low density, high specific surface area and hydroxyl groups on their surface, show a high adsorption ability (up to $2630 \mathrm{mg}^{-\mathrm{g}^{-1}}$ ) for organic pollutants (e.g., methylene blue) [69]. Graphene oxide/carboxymethyl 
Fig. 2 Material selection diagram: adsorption ability plotted against equilibrium time. It is helpful to provide guidelines for paper-based biosensor fabrication [67-85]

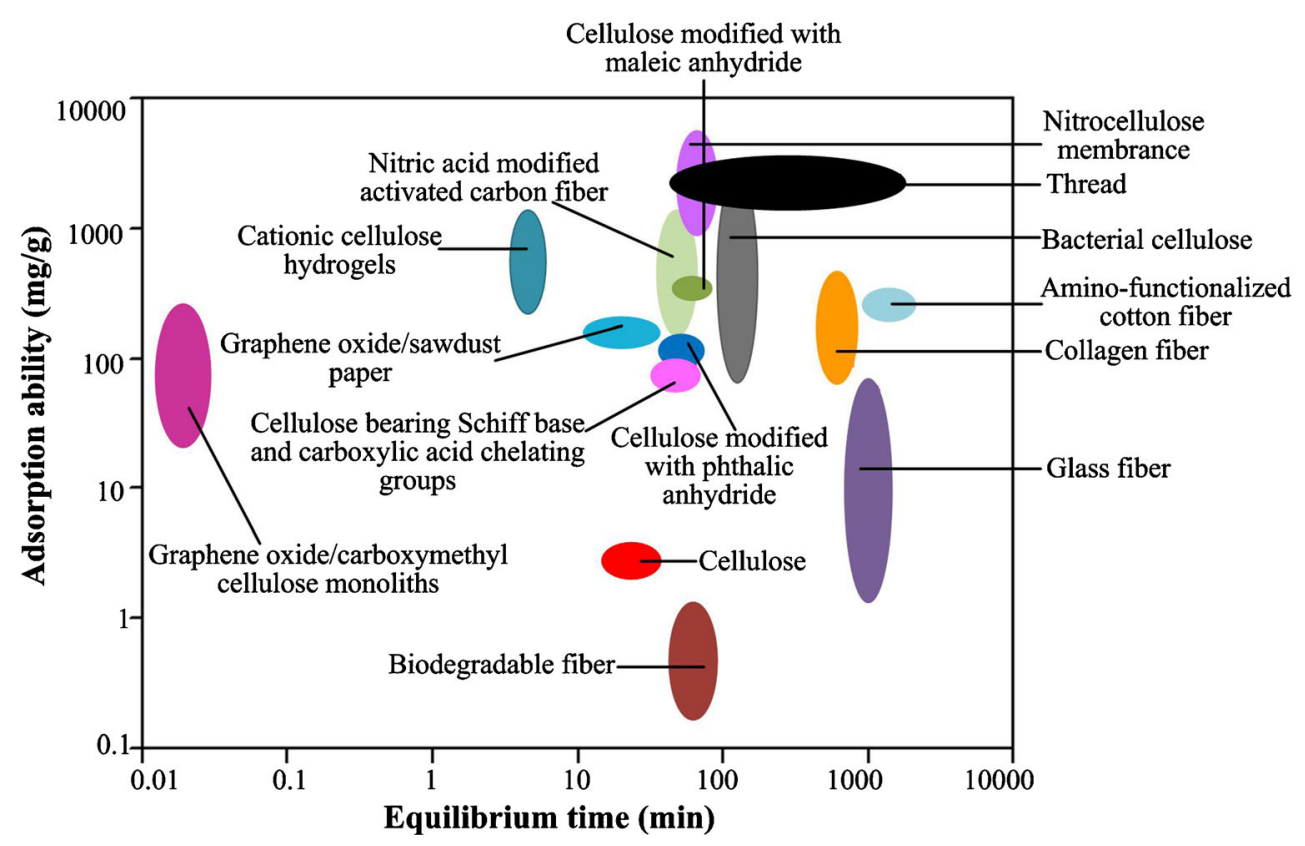

cellulose monoliths with a unidirectional porous structure have a compressive strength of $70 \mathrm{kPa}$, surfaces with abundant hydroxyl and carboxyl groups, a highest porosity of $96 \%$ and an adsorption capacity ranging from 46.13 to $82.93 \mathrm{mg} . \mathrm{g}^{-1}$ [71]. Cellulose modified with maleic and phthalic anhydride displays better adsorption capacity than cellulose, with maximum adsorption capacities up to $370 \mathrm{mg} \cdot \mathrm{g}^{-1}$ and $111 \mathrm{mg} \cdot \mathrm{g}^{-1}$, respectively, by introducing carboxyl groups [70].

Cotton fiber Cotton fiber, a natural material, has a specific surface area of $37 \mathrm{~m}^{2} \cdot \mathrm{g}^{-1}$ and contains hydroxyl groups on its surface, which can be modified with nitric acid, amino or collagen to change its structure or surface chemical groups to improve the adsorption capacity for molecules (e.g., 2, 4dichlorophenoxyacetic acid [72], active brilliant red X-3B dye [73] and proteins) on its surface [74, 75]. Additionally, the high hydrophilicity and high porosity of cotton fiber can provide a porous network architecture, which contributes to the high fluid flow driven by capillary force in cotton fiber.

Glass fiber Glass fiber is a kind of synthetic fiber and is formed of silica-based thin strands. Glass fiber has a diameter ranging from 15.2 to $18.4 \mu \mathrm{m}$, a tensile strength ranging from $0.24 \mathrm{~N}$ to $0.4 \mathrm{~N}$ [95], a density ranging from $2.5 \mathrm{~g} . \mathrm{cm}^{-3}$ to $2.7 \mathrm{~g} . \mathrm{cm}^{-3}$ [95], and a high modulus of elasticity of $60 \mathrm{GPa}$ [96]. Glass fiber has been widely utilized as a support matrix in paperbased devices for adsorption of biomolecules (e.g., proteins, nucleic acids and nanoparticles) [76]. This material has the advantages of good chemical resistance, good tensile strength, excellent dimensional stability and high insulation ability [97].
Nitrocellulose membranes NC membranes are created by the reaction of cellulose and nitric acid [98]. The surfaces of NC membranes, containing the strong dipoles of nitrate groups, can interact with the dipoles of peptide bonds on a protein surface and then immobilize the protein on the NC membrane. Furthermore, NC membranes have a negative charge and can adsorb biomolecules with a positive charge (e.g., antibodies, antigens or other proteins) through electrostatic adsorption. HF-90, HF-135 and HF-180 are the three main types of NC membranes used in POCT. The porosities and pore sizes of HF-90, HF-135 and HF-180 are $80.65 \%, 79.54 \%$ and $78.67 \%$ and $10-55 \mu \mathrm{m}, 10-30 \mu \mathrm{m}$ and $9-14 \mu \mathrm{m}$, respectively. The adsorption capacities of NC membranes for proteins are affected by its pore size [77], and the maximum adsorption capacities of HF-180, HF-135 and HF-90 are $2038 \mathrm{mg} . \mathrm{g}^{-1}$, $1810 \mathrm{mg} \cdot \mathrm{g}^{-1}$ and $1135 \mathrm{mg} \cdot \mathrm{g}^{-1}$, respectively.

Thread Threads (e.g., spun thread, cotton yarn and cotton thread) are composed of a tremendous number of fibers tightly bonded with one another to form a twisted structure [99]. Because of the high tensile strength and flexibility, easy operation and modification, good wicking capacity, absorption capacity and fluid capillary flow of thread, it with excellent potential to form hydrophilic or hydrophobic transport channels has been used as the support material of POCT devices [99, 100]. Moreover, the pores of flow channels in threads show a wide variety of interfiber gap sizes and woven/twisted interstitial porosities and spaces. Thus, the properties of threads are affected by many factors such as porosity and pore size. Additionally, the specific surface area of thread is limited, and these patterning and printing 


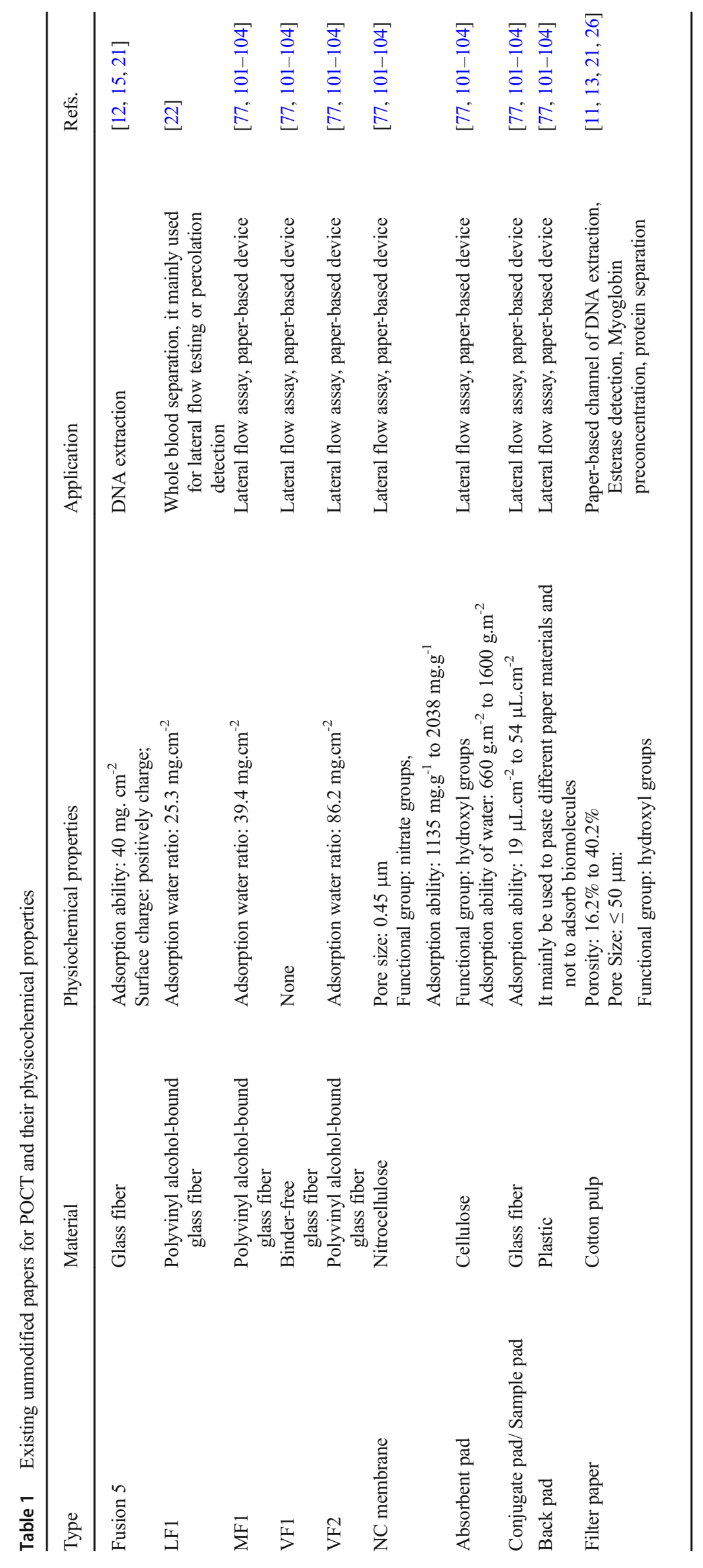


technologies are difficult to use for the fabrication of POCT devices [100].

\section{Existing unmodified papers used in paper-based POCT}

To satisfy the development of POCT technologies, different types of papers and nanomaterials have been used to fabricate paper-based devices, as illustrated in Table 1.

LFA strips, the most commonly used paper-based microfluidic devices for sample detection in POCT, mainly include adsorption pads, NC membranes, conjugate pads, sample pads and back pads $[101,105,106]$. In LFAs, NC membranes, based on a versatile porous material with nitrate groups on its surface, can immobilize nucleic acids, proteins and other biomolecules through hydrophobic, noncovalent or electrostatic interactions [98]. Adsorption pads can adsorb water based on their good hydrophilicity. Conjugate pads and sample pads can store colloidal gold particles and samples because of their good hydrophilic and release properties. The adsorption pad, NC membrane, conjugate pad and sample pad are pasted on the back pad. For example, for nucleic acid detection, NC membranes have been used as a reaction substrate of LFAs to immobilize nucleic acid sequences by streptavidin-biotin reactions because streptavidin can be directly adsorbed on NC membranes by physical adsorption $[64,102,107]$ or UV-light cross-linking between two oligonucleotide sequences and the NC membrane [108]. For protein detection, NC membranes have been used to directly immobilize antibodies through physical adsorption [101]. Thus, the performance of LFAs is affected by several factors, including the properties of sample pad, conjugate pad, absorbent pad and signaling molecules.
In addition, filter paper has also been directly utilized to prepare paper-based channels to drive liquid flow through filter paper and reach the reaction area based on capillary force [21]. Additionally, Whatman ${ }^{\circledR}$ filter paper No. 1 has been used to fabricate paper-based devices to detect esterase [26]. Moreover, filter paper with chemical groups on its surface can immobilize chemical molecules through chemical reactions [109].

Besides the above mentioned paper materials, various types of nanomaterials, such as carbon dots (CD) [110, 111], silver nanoparticles (AgNP) [41], AuNPs [38, 39, 43, 112, 113] and AuNPs@ $\mathrm{SiO}_{2} \mathrm{NPs}$ [25] and other nanomaterials $[48,50,55]$, have also been used as detection probes to generate colorimetric signals on the test strips of LFAs (Table 2). The nanoparticles on LFAs are modified with different biomolecules (e.g., antibody), which can immobilize on conjugation pad and interact with target and then bind the biomolecules on test line for detection.

\section{Paper modification approaches for sample pretreatment}

Biological samples generally contain complex components, which makes direct detection challenging. Thus, sample pretreatment procedure before detection, including sample storage and collection, sample separation, nucleic acid extraction and sample pre-concentration, is necessary. For the POCT applications, different types of papers modified with various reagents to change their physicochemical properties (e.g., chemical groups and surface charge) and to enhance their performances for sample pretreatment have been used to prepare the paper-based microfluidic devices, as summarized in

Table 2 An overview on commonly used nanomaterials for modification of papers for use in LFAs

\begin{tabular}{|c|c|c|c|}
\hline Material type & Paper type & Application & Refs. \\
\hline AuNP & $\begin{array}{l}\text { FP membrane, } \mathrm{NC} \text { membrane, filter } \\
\text { paper }\end{array}$ & $\begin{array}{l}\text { Nucleic acid, C-reactive protein, photometric, listeria monocytogene } \\
\text { serotypes and digoxigenin detection, etc. }\end{array}$ & {$[34-38]$} \\
\hline Carbon dots and AgNP & NC membrane & Zearalenone detection & {$[41]$} \\
\hline Polymer nanoparticles & NC membrane & Nucleic acids detection & {$[55]$} \\
\hline Quantum dots & Whatman filter paper, NC membrane & $\begin{array}{l}\text { Mercury, fumonisins, tetracycline antibiotics and enrofloxacin } \\
\text { detection }\end{array}$ & [29-32] \\
\hline Gold nanorods & NC membrane & E.coli $\mathrm{O} 157: \mathrm{H} 7$ detection & {$[53]$} \\
\hline Gold nanocage & NC membrane & Immunoglobulin $\mathrm{G}$ detection & {$[52]$} \\
\hline $\begin{array}{l}\text { Red fluorescent } \\
\text { nanoparticles }\end{array}$ & NC membrane & Multi $\beta$-agonist residues detection & {$[51]$} \\
\hline Metal-organic framework & Filter paper & Peroxidase mimetic detection & {$[50]$} \\
\hline $\mathrm{Cu}-\mathrm{Pd}$ nanoparticles & Filter paper & Glucose detection & [48] \\
\hline
\end{tabular}

$A u N P$ gold nanoparticle, $A g N P$ Silver nanoparticles 


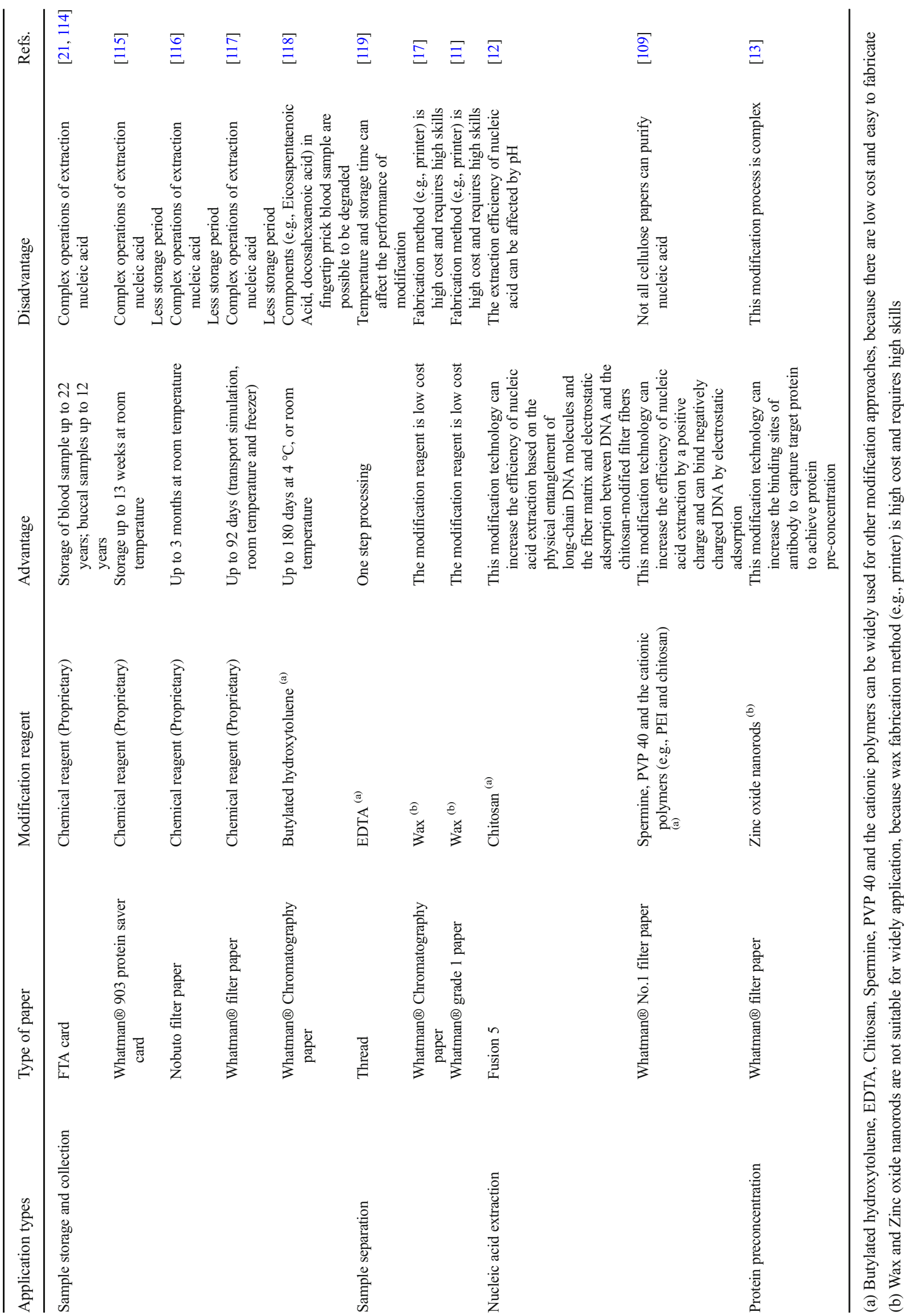


Fig. 3 Paper modification approaches for sample storage and collection and sample separation. a. Commercial papers for sample collection and storage [21, 114-117]. b. EDTAtreated modified technology for one step whole blood plasma separation [119]

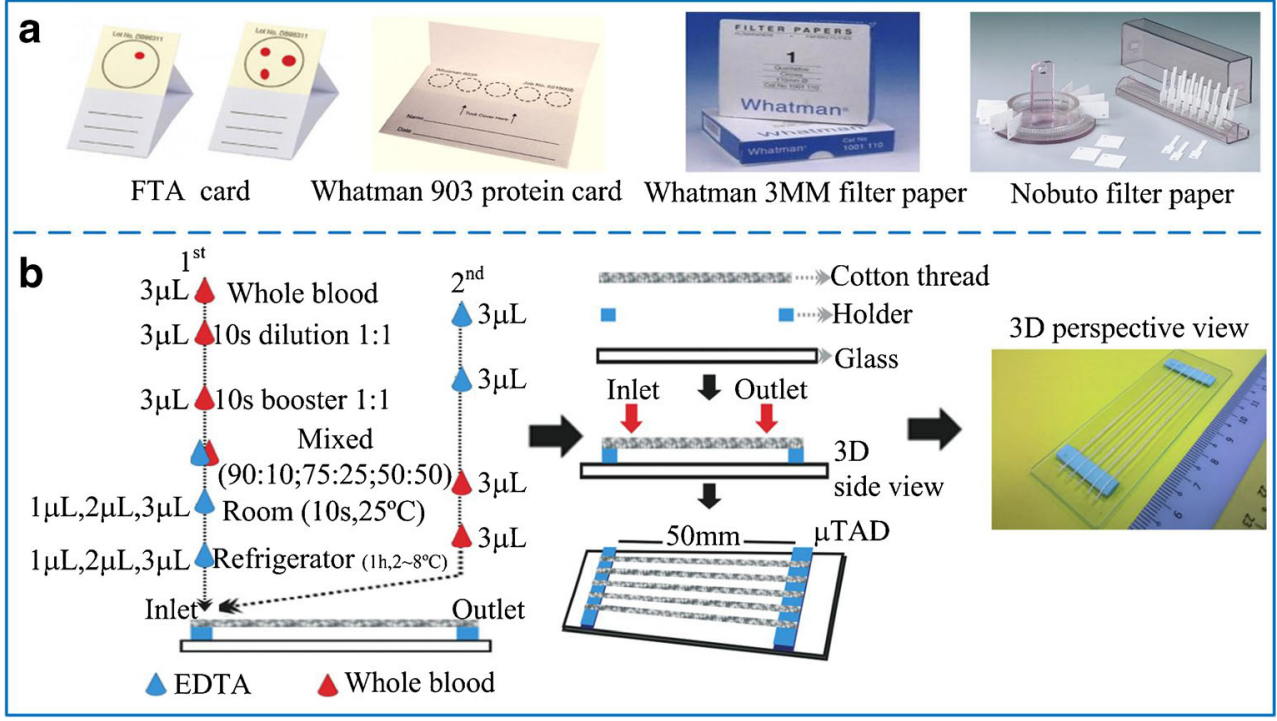

Table 3. In the following section, we will introduce the main paper modification approaches for sample pretreatment.

\section{Sample storage and collection}

In most cases, biological samples (e.g., whole blood, tissue, saliva and urine) need be stored and transported at low temperature before analysis. Tubes, bottles and refrigerators are normally utilized to collect and store samples. Compared to these conventional methods, paper has the advantages of low cost, porous structure, portability and ease of use. Thus, the paper-based sample storage and collection methods have been developed and used for pretreatment of biological samples.

For storage of different biological samples (e.g., blood, tissues, cells and bacteria) on paper, various chemical reagents have been used to modify different kinds of papers to change the chemical groups on their surfaces. For example, commercial papers, such as FTA cards, Whatman ${ }^{\circledR} 903$ protein saver cards, Whatman ${ }^{\circledR} 3 \mathrm{MM}$ filter paper and Nobuto filter paper, were modified with chemical reagents to protect nucleic acids or proteins from being destroyed by bacteria or ultraviolet light (Fig. 3a) [115-117, 120]. Chromatography paper modified with butylated hydroxytoluene was used to collect and store blood sample [118]. These modified papers allow storage and collection of various samples at room temperature and are compatible with several downstream extraction methods, e.g., RNeasy Mini Blood kit [115], making them suitable for POCT applications. The sample storage periods of these papers are different and depend on the chemical reagents used for modification. For instance, Whatman ${ }^{\circledR} 3 \mathrm{MM}$ filter paper and Whatman ${ }^{\circledR} 903$ protein saver cards can store blood samples for up to 13 weeks at low temperatures $\left(\right.$ e.g., $-80^{\circ} \mathrm{C},-20$ ${ }^{\circ} \mathrm{C}$ and $4{ }^{\circ} \mathrm{C}$ ) and at $35^{\circ} \mathrm{C}[115]$. Chromatography paper can store blood samples for up to 92 days at $4{ }^{\circ} \mathrm{C}$ or room temperature [117]. Nobuto filter paper can store samples for up to three months at room temperature [116]. FTA cards can store blood samples for up to 22 years and buccal samples for up to 12 years at room temperature. However, these commercial papers have not be fully used for the sample in-result out bedside diagnosis, because they still need combine with the downstream analysis technologies (e.g., PCR [12], RT-PCR [121]) to accomplish the testing step.

\section{Sample separation}

Variability of debris components (e.g., red blood cells, inorganic salts and metabolites) in samples (e.g., whole blood, urine and sweat) can affect the accuracy of analytical results. Thus, sample separation is a necessary step to obtain targets from complex samples. But the most used lab method for sample separation, i.e., centrifugation, is expensive and not widely accessible for out-of-lab circumstance.

To realize the inexpensive and fast sample separation process, paper modification approaches have been developed for sample separation. For instance, in a thread-based device composed of cotton thread, holder and glass, ethylenediaminetetraacetic acid (EDTA) was modified on cotton thread to wick whole blood samples and separate plasma (Fig. 3b) [119]. The working principle of this device is that the scouring pretreatment using $\mathrm{Na}_{2} \mathrm{CO}_{3}$ solution is used to remove the natural wax of cotton thread and increase the wicking properties of material and the absorbability of the reagent into the thread. After this process, the surfaces of the cotton thread and polymer have positive charges and hydroxyl groups, respectively, which can induce blood clotting on their surfaces. After modification of EDTA, the cotton thread can inhibit blood clotting process by activating platelet activity. The EDTA-treated cotton thread device has lower detection limit $\left(114 \mathrm{mg} \cdot \mathrm{L}^{-1}\right)$ than that of the conventional blood analysis $\left(133 \mathrm{mg} . \mathrm{L}^{-1}\right)$. It is a low-cost, accurate and fast analytical platform for POCT in 
Fig. 4 Paper modification approaches for sample separation. a, b. Wax-based modification technology is used for sample separation $[11,17]$

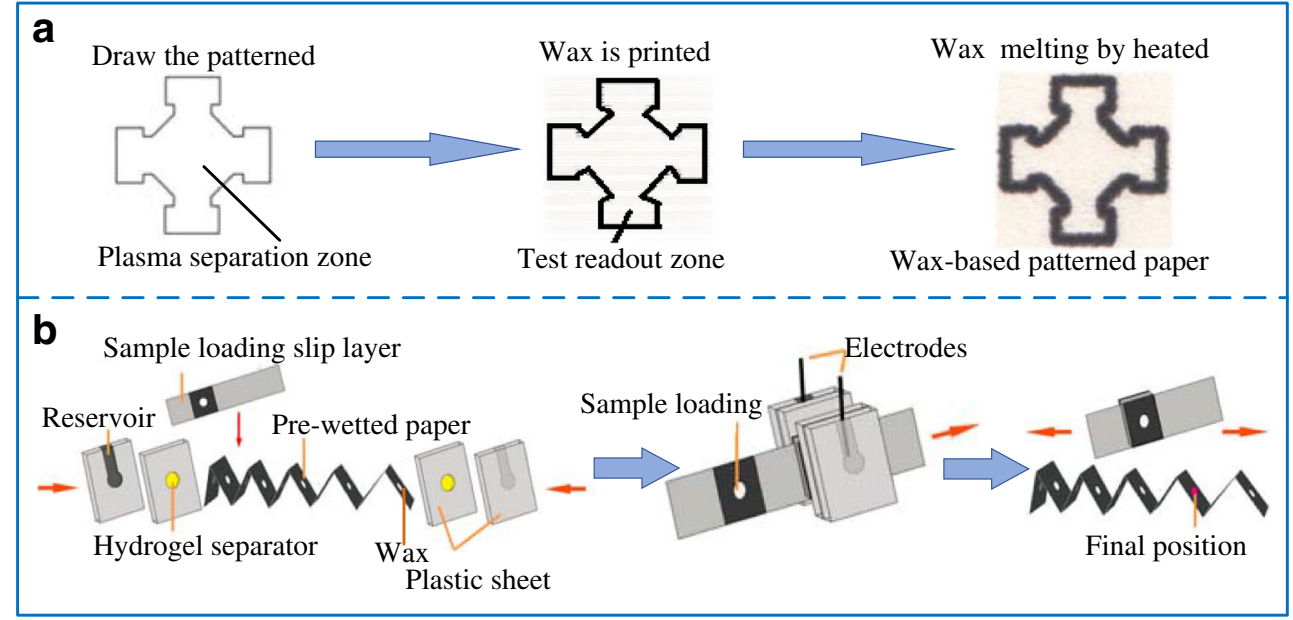

resource-limited settings. However, the performance of this device is influenced by temperature and storage time. In addition, chromatography paper modified with wax was used to prepare paper-based blood plasma separation device (Fig. 4a) [17]. This paper-based device is consisted of wax and chromatography paper, including the plasma separation zone in the center and the test area in the periphery. In the modification process, wax patterns designed by illustration software (e.g., CAD software) were printed on paper using a solid-ink printer. Then, the wax-printed paper was placed on a hotplate to melt the wax and create hydrophobic barriers which spans the device [17]. After patterning, the paper was modified with agglutinating antibodies and colorimetric chemical reagents by physical adsorption. The as-prepared device is capable of separating blood plasma based on the agglutination technique of red blood cell in the plasma separation area integrated into the device and detecting glucose for medical applications at home. However, for the application of this device, the expensive wax printer is still needed and the antibodies can easily denature, which affects the accuracy of detection result.

In another example, a paper origami-based electrophoretic device (oPAD-Eps) was fabricated by patterning wax on a slip layer and origami paper (Whatman ${ }^{\circledR}$ grade 1 paper) using CorelDraw software and a wax printer (Fig. 4b) [11]. Since the molecules can move through the paper-based substrate of oPAD-Eps device based on electrophoresis under an external electric field, the oPAD-Eps can separate fluorescent molecules, e.g., $\mathrm{Ru}(\mathrm{bpy})_{3} \mathrm{Cl}_{6}$, 4,4-difluoro-1,3,5,7,8-pentamethyl4-bora-3a, 4a-diaza-s-indacene, 8-methoxypyrene-1,3,6trisulfonic acid trisodium salt, 1,3,6,8-pyrenetetrasulfonic acid tetrasodium salt, rhodamine $6 \mathrm{G}$, methylene blue and rhodamine B [11]. Thus, this sample pretreatment device can be further integrated with other paper-based detection devices for fluorescent detection. However, it is difficult to be used
Fig. 5 Paper modification approaches for nucleic acid extraction. a. Chitosan-modified filter paper for nucleic acid extraction [12]. b. Whatman® No.1 filter paper modified with spermine, PVP 40 and the cationic polymers for nucleic acid extraction [109]

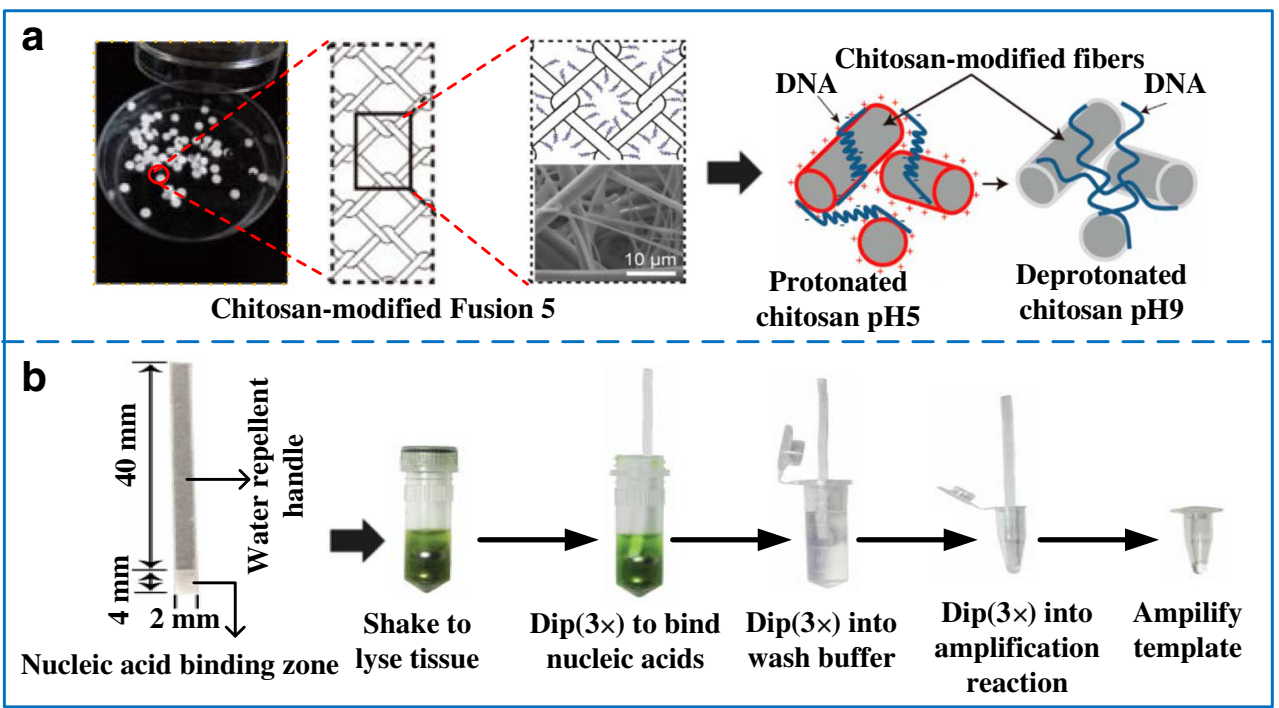


for bedside diagnosis because its needs of complex fabrication process and extra electric field. Additionally, the modification technology has a high cost because of the use of an inkjet printer.

\section{Nucleic acid extraction}

For detection of nucleic acids, nucleic acid extraction is a key step in isolating targets (e.g., DNA, RNA) from complex samples before analysis. However, the conventional extraction methods always include lysis, washing and elution procedures, which are complex, time consuming and not suitable for POCT applications.

To achieve rapid and simple extraction of nucleic acid, several papers (e.g., Fusion 5, glass fiber) have been used. However, the extraction efficiencies of these papers are still poor due to the nonspecific absorbance of cell debris and interferents (e.g., hemoglobin) on paper, which affects the extraction purity and sensitivity of downstream analysis. To enhance the extraction efficiency, several modification approaches have been utilized to change the surface charges of paper for nucleic acid extraction. For example, chitosan was used to modify Fusion 5 for paper-based DNA extraction (Fig. 5a) [12]. The device is composed of Fusion 5, PDMS membrane and PMMA. Fusion 5 was inserted into PDMS membrane and then sandwiched by two PMMA layers. In the modification process, Fusion 5 was modified sequentially by oxygen plasma activation, chitosan treatment, deionized water washing and vacuum drying. The capture principle of DNA in the modification process is based on the physical entanglement of long-chain DNA molecules and the fiber matrix and electrostatic adsorption between DNA and the chitosanmodified filter fibers. With this modification, the capture efficiencies of K562 human genomic DNA (up to 98\%) and bacteriophage $\lambda$-DNA (up to $95 \%$ ) are significantly improved. Fusion 5 can also preconcentrate $\lambda$-DNA from a diluted sample by more than 30-fold. But on the other hand, the extraction efficiency of nucleic acids of this device is affected by $\mathrm{pH}$. The device requires syringe pump and valve to achieve automated extraction of DNA from a small volume of sample, indicating that it still needs improve its portability for bedside diagnosis. In addition, Whatman ${ }^{\circledR}$ No. 1 filter paper was modified with spermine, polyvinylpyrrolidone (PVP) 40 and cationic polymers (e.g., polyethylenimine (PEI), dopamine, 3-aminopropyl trimethoxysilane (APTMS) and chitosan) to bind DNA/RNA from animal, plant and microbe samples (Fig. 5b) [109]. In the binding process, the surface of the modified filter paper has a positive charge and can bind negatively charged DNA by electrostatic adsorption. The binding ability of nucleic acids on the chitosan- and PEI-modified filter paper is better than that of other compounds. The cellulose dipstick is composed of a wax impregnated handle and nucleic acid binding region.
Fig. 6 Paper modification approaches for preconcentration. Paper modified with zinc oxide nanorods for Myoglobin preconcentration [13]

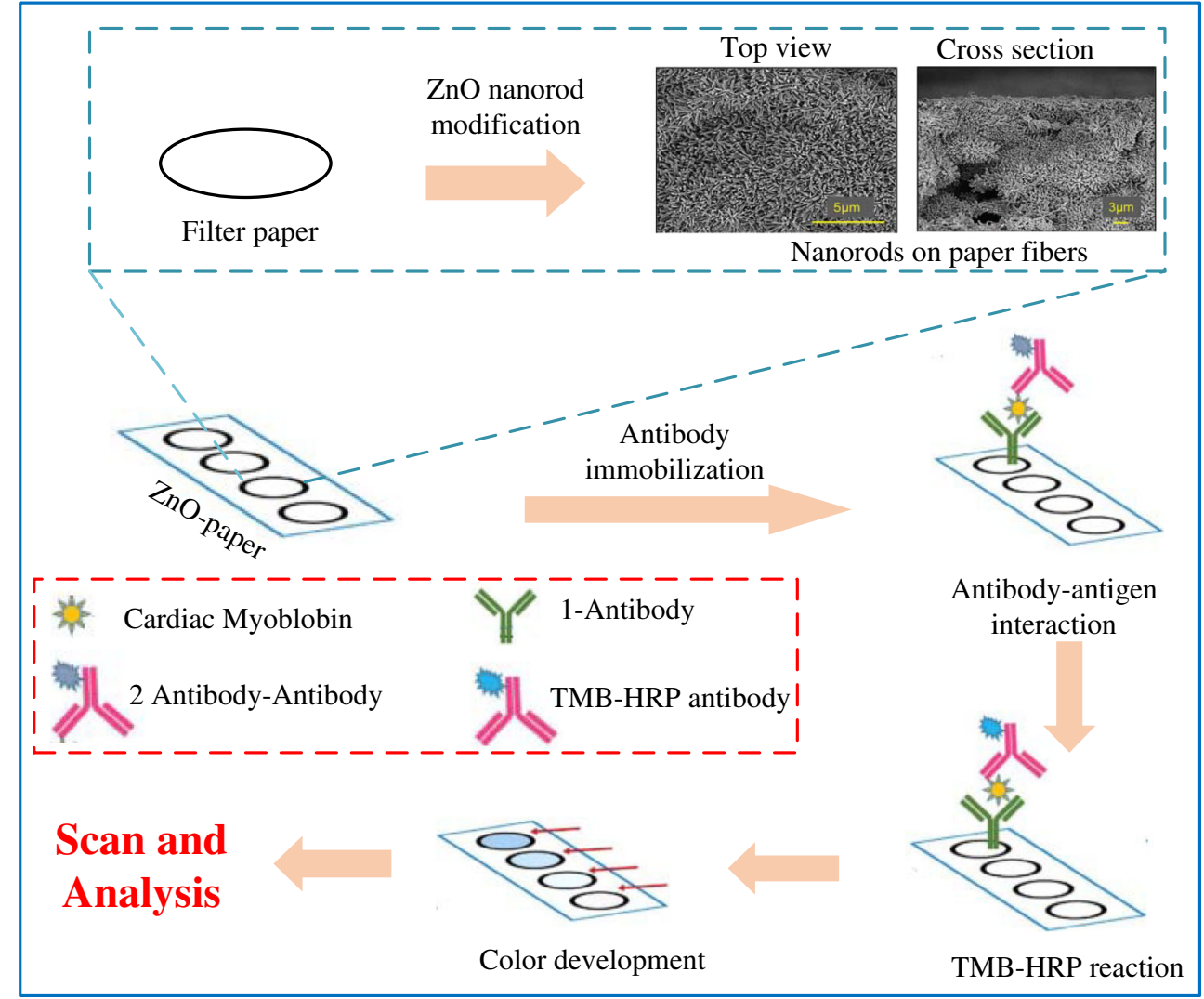




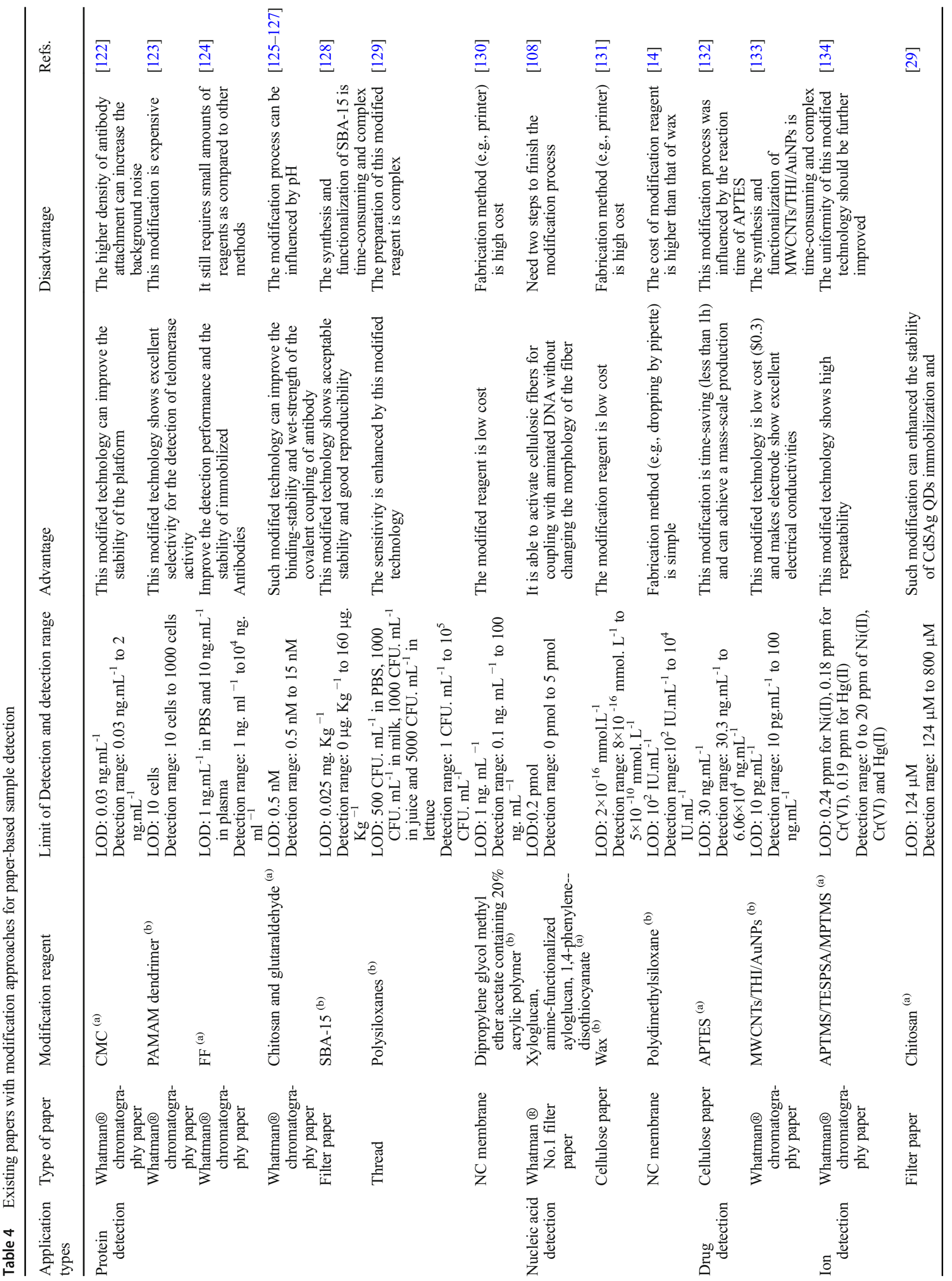


The cellulose-based dipstick can extract nucleic acid within 30 second without any pipette or electrical equipment and can combine with simple portable amplification device for POCT applications. In short, these modification approaches for filter paper can improve the extraction efficiency of DNA and can be integrated into paper-based devices for the rapid testing of nucleic acids in POCT.

\section{Sample preconcentration}

At the early stage of diseases, biomarkers with low concentrations are present in samples. The rapid detection of targets with low concentrations still meets challenges. Sample preconcentration process before detection is thus needed. Conventional preconcentration methods (e.g., centrifugation and filtration) are complex, expensive and time-consuming, making them difficult to be integrated into the POCT devices.

To address this issue, various fast, portable and inexpensive technologies for sample preconcentration have been developed. For instance, Whatman ${ }^{\circledR}$ No. 1 filter paper modified with zinc oxide nanorods using a hydrothermal method was developed to fabricate paper-based ELISA device for preconcentration of myoglobin (Fig. 6) [13]. The $\mathrm{ZnO}$ nanostructured-paper composite can form the oriented micro- or nanostructures on paper to provide the high surface area of binding sites, which contribute to the immobilization of biomolecules. And the modified paper treated with 3APTES through salinization can increase the antibody binding sites (amides) on the paper surface to capture the target protein (myoglobin) for protein preconcentration. This device can detect myoglobin based on the antigen-antibody interaction. And the ELISA testing result of this device indicates that the preconcentration efficiency of biomarkers from a diluted solution (myoglobin $<50 \mathrm{nM}$ ) was enhanced 3-fold compared to that of the unmodified paper. However, the $\mathrm{ZnO}$ nanostructure-paper composite cannot independently use for POCT because it needs to combined with other biosensors.

The above examples show that various papers have been modified with different chemical reagents for sample pretreatment. These modification approaches have potential for fabricating functional devices with hydrophobic patterns and enhancing the performance of paper-based devices.

\section{Paper modification approaches for sample detection}

For the rapid detection of different targets (e.g., proteins, nucleic acids and ions/chemical molecules), various paper modification approaches have been used to improve the detection efficiency by changing the physicochemical properties of papers (e.g., chemical groups, hydrophobicity/hydrophobicity, wet strength and surface charge) (Table 4). 


\section{Protein detection}

Proteins in whole blood, urine, saliva and sweat have been widely used as biomarkers for detection of various diseases [137]. Paper-based devices have been developed and utilized to detect different proteins $[27,35,138]$. However, the low detection efficiency of the paper-based devices limits their further applications in POCT.

To address this, different modification approaches have been developed to change the features of papers, including the surface functional groups, wet strength and specific surface area. For example, Whatman ${ }^{\circledR}$ chromatography paper was modified with carboxymethyl cellulose (CMC) to form a linker for immobilizing biomolecules in a hydrophilic barrier made of wax as reaction region to promote the functionality and stability of paper-based ELISA devices (Fig. 7a) [122]. The device was used to detect tuberculin based on the antigenantibody interaction, and its hydrophilicity increased by $\mathrm{CMC}$ can reduce non-specific binding of random proteins to improve its detection sensitivity. In the modification process, 1ethyl-3-(-3-dimethylaminopropyl) carbodiimide hydrochloride/N-hydroxy-succinimide (EDC/NHS) was crosslinked with the CMC-modified cellulose surface to produce NHS ester groups, which can enhance the specific binding between the paper substrate and the ligands or proteins by covalent conjugation. This modification technology can achieve a detection limit of 0.03 ng. $\mathrm{mL}^{-1}$ for tuberculin protein. The CMCmodified paper shows potential as an equipment-free diagnostic platform. However, the higher density of antibody attachment on paper substrate can increase the background noise and wax printer is expensive. Additionally, Whatman ${ }^{\circledR}$ chromatography paper was modified with polyamidoamine starburst dendrimer (PAMAM dendrimer) to fabricate a paper-based device for the detection of telomerase activity (Fig. 7b) [123]. The modification approach functionalized the paper surface with amino groups, which can improve the efficiency of biomolecules immobilization. The paper-based device was fabricated by hand drawing with using a template and was used to detect telomerase activity based on the hybridization of Cy5 modified single strand DNA probes with telomerase extension products. The PAMAM-based device is a simple and amplification-free fluorescence assay, making it suitable for disease diagnosis at bedside. However, this modification is expensive. Additionally, a novel peptide of diphenylalanine (FF) was used to modify Whatman ${ }^{\circledR}$ chromatography paper to prepare nanocomposite electrodes for detection of alpha-fetoprotein (AFP) (Fig. 7c) [124]. The device is composed of a lower sheet of plastic and an upper layer of cellulose paper modified with silver-graphene printed electrodes and uses antibody captured target protein to generate electrical response relevant to the concentrations of target protein. In the modification process, FF not only enhances the stability of immobilized antibodies via amine-aldehyde reactions, but also increases the wet strength of paper by forming paper-plastic integrated chips. The paper-based device can screen AFP with a range from $1 \mathrm{ng} \cdot \mathrm{mL}^{-1}$ to $10^{4} \mathrm{ng} \cdot \mathrm{mL}^{-1}$ and achieve a detection limit of 10 ng. $\mathrm{mL}^{-1}$. It can be integrated into a miniaturized portable
Fig. 7 Paper modification approaches for protein detection. a. Cellulose paper modified with CMC through EDC/NHS crosslinked for tuberculin-purified protein detection [122]. b. Paper modified with PAMAM dendrimer for telomerase activity detection [123]. c. Cellulose modified with FF for Alphafetoprotein detection [124]

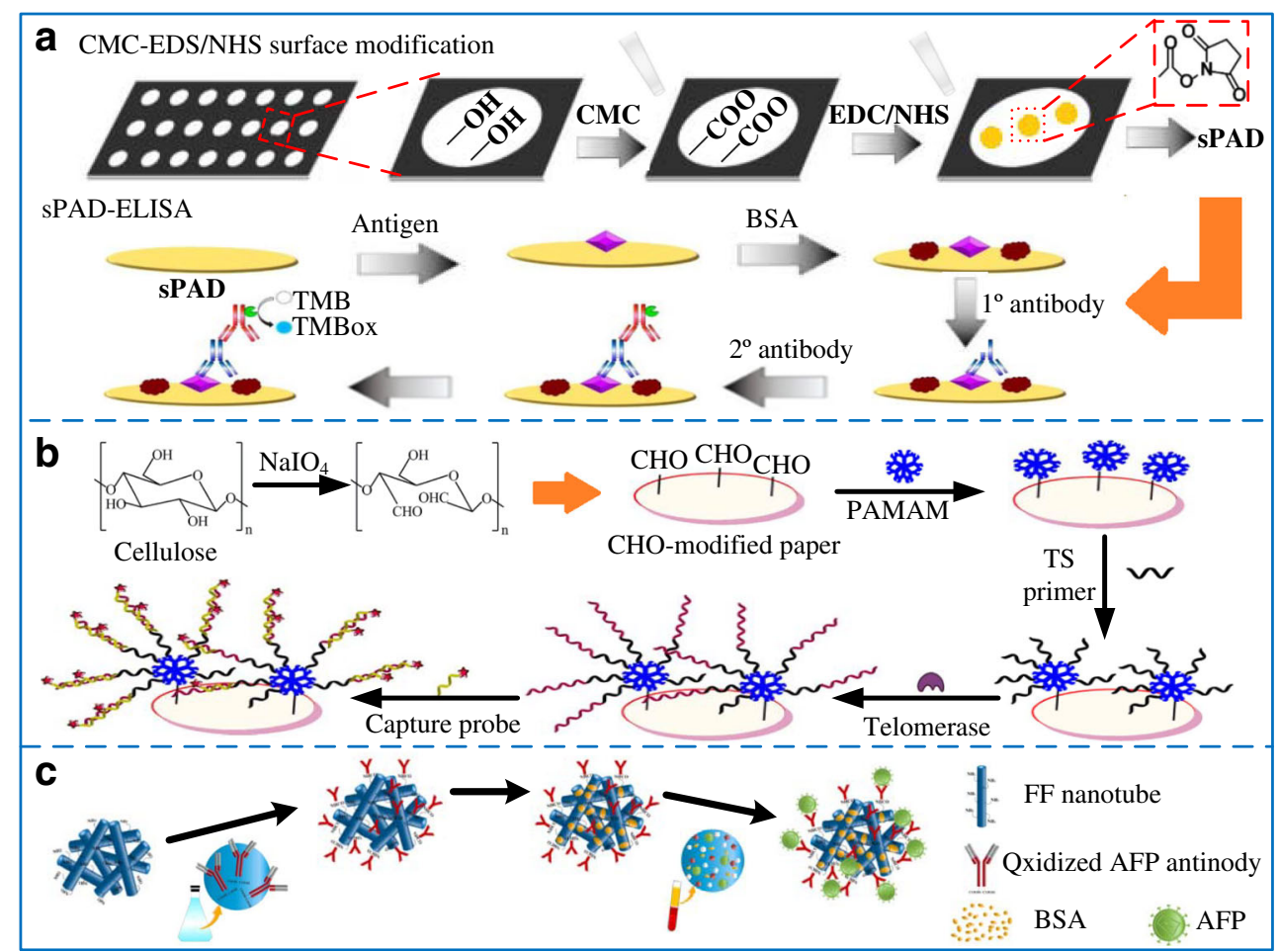


Fig. 8 Paper modification approaches for protein

detection. a. Paper modified with chitosan for protein detection [125]. b. Paper modified with SBA-15 technology for gliadin detection [128]. c. Thread modified with polysiloxanes technology for Salmonella enterica Serotype Enteritidis detection [129]. d. Dipropylene glycol methyl ether acetate containing $20 \%$ acrylic polymer is printed on the surface of the NC membrane to form barrier to achieve multistep operations [130]

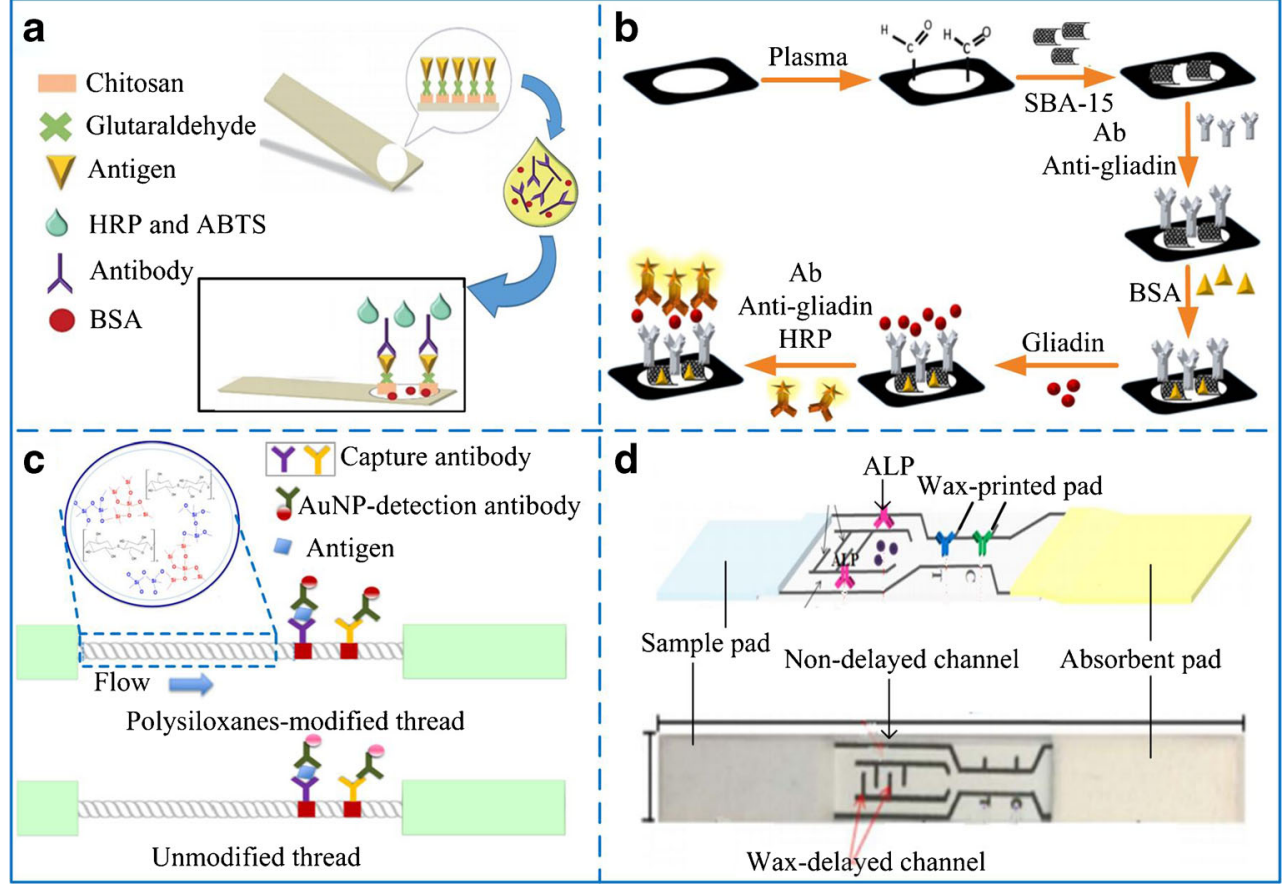

device as a paper-based biosensor for POCT. However, it still requires small amounts of reagents (e.g., hexafluoroisopropanol) compared to other methods.

Similarly, chromatography paper was modified with chitosan and glutaraldehyde to enhance the immobilization efficiency of antibody (e.g., ubiquitin or enhanced green fluorescent protein, cherry protein) on paper in the paper-based ELISA device (Fig. 8a) [125]. The device was fabricated by attaching paper disk to a plastic strip using double-sided tape and then building the straw region on the paper surface. And the modification process changes the hydrophobicity of the paper surface with varying the amounts of chitosan-glutaraldehyde. Based on the antigen-antibody interaction on the paper substrate, the target antibodies can be captured by protein, which leads to a color change on the paper. The testing results showed that the linear range of the targeted antibodies was 0.5 $\mathrm{nM}$ to $15 \mathrm{nM}$. Such modification technology is easy to perform without need of any special reagent or instrumentation and can also be used for paper-based enzyme and DNA assays based on the covalent coupling of enzymes and DNA molecules, making the paper-based device suitable for more POCT applications. However, the reactivity of glutaraldehyde and the zeta potential of chitosan are influenced by $\mathrm{pH}$, which can affect the immobilization efficiency of protein on the paper surface. In another example, filter paper was modified with the amino-functionalized mesoporous material Santa Barbara Amorphous (SBA-15) to achieve the fluorescent detection of gliadin (Fig. 8b) [128]. The paper-based device used wax to prepare hydrophobic barriers to form microzone for reaction and mesoporous material to modify paper to provide more aldehyde groups on paper to enhance its immobilization efficiency of biomolecules. The modification process can improve the immobilization capacity of anti-gliadin antibodies on the paper surface by increasing the specific surface area of nanoporous structures and achieving the amino functionalization of SBA-15. The device achieves a detection limit of $0.025 \mathrm{mg} \cdot \mathrm{kg}^{-1}$, good reproducibility and detection stability. Whereas, the synthesis and functionalization processes of SBA-15 are time consuming and complex. And the paper-based device is not suitable for fast detection of gliadin at resource-limited settings because it need to use extra equipment for analysis of fluorescent signal.

Moreover, paper and cotton thread were modified with hydrophobic reagents to enhance the detection efficiency of protein by delaying sample fluid flow rate. For example, polysiloxanes was modified on the surface of cotton thread and the fabricated cotton thread-based device was used to detect Salmonella enterica Serotype Enteritidis based on the antigen-antibody reaction (Fig. 8c) [129]. Similar with the fabrication of LFA, the thread-based device is composed of thread, adsorption pad, conjugation pad, sample pad and back pad. It uses antigen-antibody reaction to finish detection and incorporates polysiloxanes to change the hydrophobic of paper-based channel. The modification process used polysiloxanes to reduce the pore size and porosity of the cotton thread by forming hydrophobic barriers on the cotton thread. The detection limit is enhanced approximately 10 fold compared to that of the unmodified thread-based device. However, the preparation of this modified reagent is complex. Additionally, dipropylene glycol methyl ether acetate containing $20 \%$ acrylic polymer was modified on a NC membrane surface to create hydrophobic patterns, which can decrease the 
sample fluid flow and automate the multistep analysis on the paper-based ELISA device (Fig. 8d) [130]. The device was fabricated by printing dipropylene glycol methyl ether acetate containing $20 \%$ acrylic polymer on NC membrane to prepare hydrophobic barrier to form different regions, including nondelayed channel, a wax-delayed channel a test zone and a control zone. As an automated, one-step and portable paperbased ELISA device, it can be used for bedside diagnosis. However, this modification process needs extra equipment (e.g., wax printer). In a word, the performances of these modification approaches can be further enhanced by optimization of the modification processes with simpler procedures and equipment.

\section{Nucleic acid detection}

Nucleic acids, as one of the most fundamental biological substances in all organisms, have been used as typical biomarkers [34]. Detection of nucleic acids plays an important role in disease diagnosis. Unmodified paper cannot achieve high performance in nucleic acid detection due to its limited physicochemical properties. For example, unmodified Fusion 5 has low extraction efficiency of nucleic acid due to the higher adsorption ability of nonspecific biomolecules on its surface
$[18,21]$. The modification approaches of papers are thus needed for developing the paper-based nucleic acid detection devices.

For example, Whatman® No. 1 filter paper was modified with 1,4-phenylenediisothiocyanate and the fabricated paper device was used to detect nucleic acid based on the DNA hybridization reaction (Fig. 9a) [108]. In the modification process, the surface of Whatman ${ }^{\circledR}$ No. 1 filter paper was activated with aminated xyloglucan and xyloglucan to change the chemical groups on the fibers to react with aminated DNA without changing the morphology of fibers. The functionalized filter paper can accurately differentiate sequence-tagged amplicons of canine and human DNA in mock forensic samples. Moreover, such paper as a rapid and specific diagnostics can be used in real-life situations. In addition, papers modified with hydrophobic reagents were used to improve their detection efficiencies for nucleic acid detection. For instance, cellulose paper was modified with wax to form hydrophobic and insulating patterns on paper sheet and the unprinted wax area on paper with good hydrophilicity and porous structure was used as reaction area for the target in samples. Then the $\mathrm{Ag} /$ $\mathrm{AgCl}$ ink was screen-printed on the paper surface as electrodes to form paper-based electrochemical DNA assay (Fig. 9b) [131]. The prepared paper-based DNA assay was
Fig. 9 Paper modification approaches for nucleic acid detection. a. 1,4-phenylenedisothiocyanate-based modification technology for nucleic acid extraction [108]. b. Wax-based modification technology is used to form hydrophobic and insulating patterned paper sheet for screenprinting electrodes in paper-based electrochemical DNA assay [131]. c. PDMS-based modification technology is used to fabricate the hydrophobic barrier on the NC membrane for improving the sensitivity of strip [14]

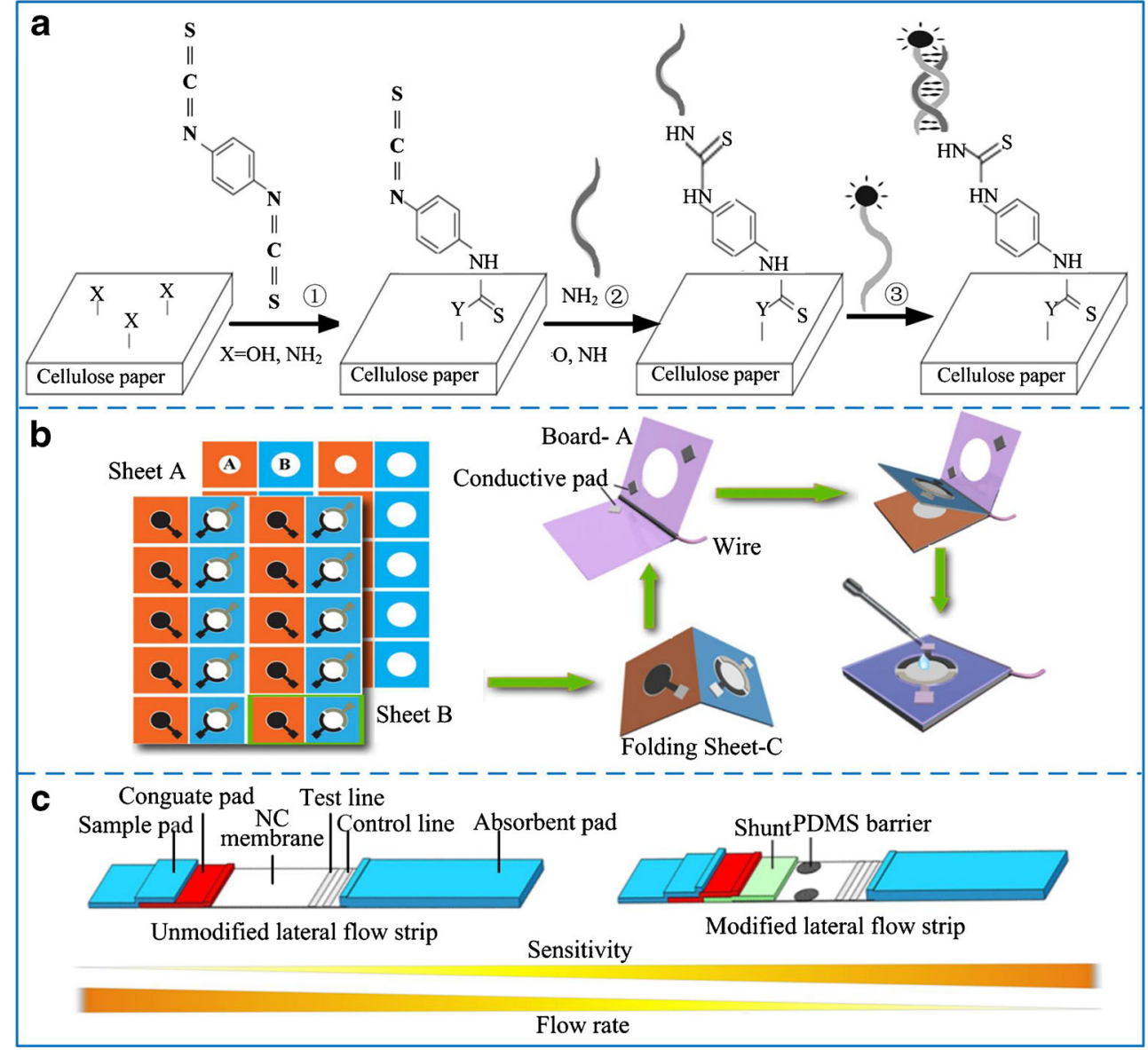


successfully used to electrochemically detect the concentrations of DNA in samples. It shows not only good detection sensitivity but also the capability for integration into emerging electronic devices for the development of high-throughput POCT devices in resource-limited settings. However, this process still needs extra wax printer. Besides wax, polydimethylsiloxane (PDMS) was also added on the NC membrane surface of LFA test strip to create hydrophobic barrier to delay fluid flow (Fig. 9c) [14]. The detection sensitivity of the prepared LFA for nucleic acids based on the nucleic acid hybridization reaction was improved 2-fold over that of the unmodified LFAs. Furthermore, the combination of a shunt and PDMS barrier in the LFAs yielded a 10-fold improvement in detection sensitivity over that of the unmodified LFAs. It can be utilized for bedside diagnosis or resource-limited settings.

\section{Drug detection}

Drugs have been extensively utilized to treat, control and prevent diseases in human or animals. At present, various paperbased devices have been developed to detect drug concentrations in samples. But the low detection sensitivity of the paper-based devices is still a problem during their applications.

To handle this problem, several modification approaches by changing the surface groups on papers have been developed and utilized to improve the performance of the paper- based devices. For example, cellulose paper was modified with 3-triethoxysilylpropylamine (APTES) and the prepared paper-based test strip was used to detect oxitetracycline (OXY) through observing color change (Fig. 10a) [132]. The modification method can aminate the paper surface using APTES based on the self-assembly approach, because the amine group can bind metal ions ( $\mathrm{Fe}(\mathrm{III})$ and $\mathrm{Cu}(\mathrm{II}))$ to form color. The detection concentration of OXY using this device is as low as $30 \mathrm{ng} \cdot \mathrm{mL}^{-1}$. This device is inexpensive, equipmentfree and environmental-friendly, making it suitable for resource-limited setting. However, this modification process needs complex approach and is influenced by the reaction time of APTES. Furthermore, Whatman ${ }^{\circledR}$ chromatography paper was modified with multiwalled carbon nanotubes (MWCNTs)/thionine (THI)/gold nanoparticles (AuNPs) nanocomposites, which function as the screen-printed working electrodes on paper for the detection of $17 \beta$-estradiol (Fig. 10b) [133]. The prepared paper-based device was used to detect $17 \beta$-estradiol based on electronic signal response. The modification process increases the specific surface area, which can improve the immobilization capacity of $17 \beta$ estradiol antibodies, allowing a higher density load of electroactive materials on paper surface to enhance the electrochemical current. The fabricated paper device has a wide linear detection range of $10 \mathrm{pg} \cdot \mathrm{mL}^{-1}$ to $100 \mathrm{ng} \cdot \mathrm{mL}^{-1}$ and a detection limit of $10 \mathrm{pg} \cdot \mathrm{mL}^{-1}$. To achieve the really POCT, it still needs to develop a wireless portable electrochemical
Fig. 10 Paper modification approaches for drug detection. a. Cellulose paper modified with APTES to prepare paper-based color test strip for oxitetracycline (OXY) detection [132]. b.

Whatman ${ }^{\circledR}$ chromatography paper modified with MWCNTs/ THI/ AuNPs Nano composites to prepare the screen-printed working electrodes for $17 \beta$-estradiol detection [133]

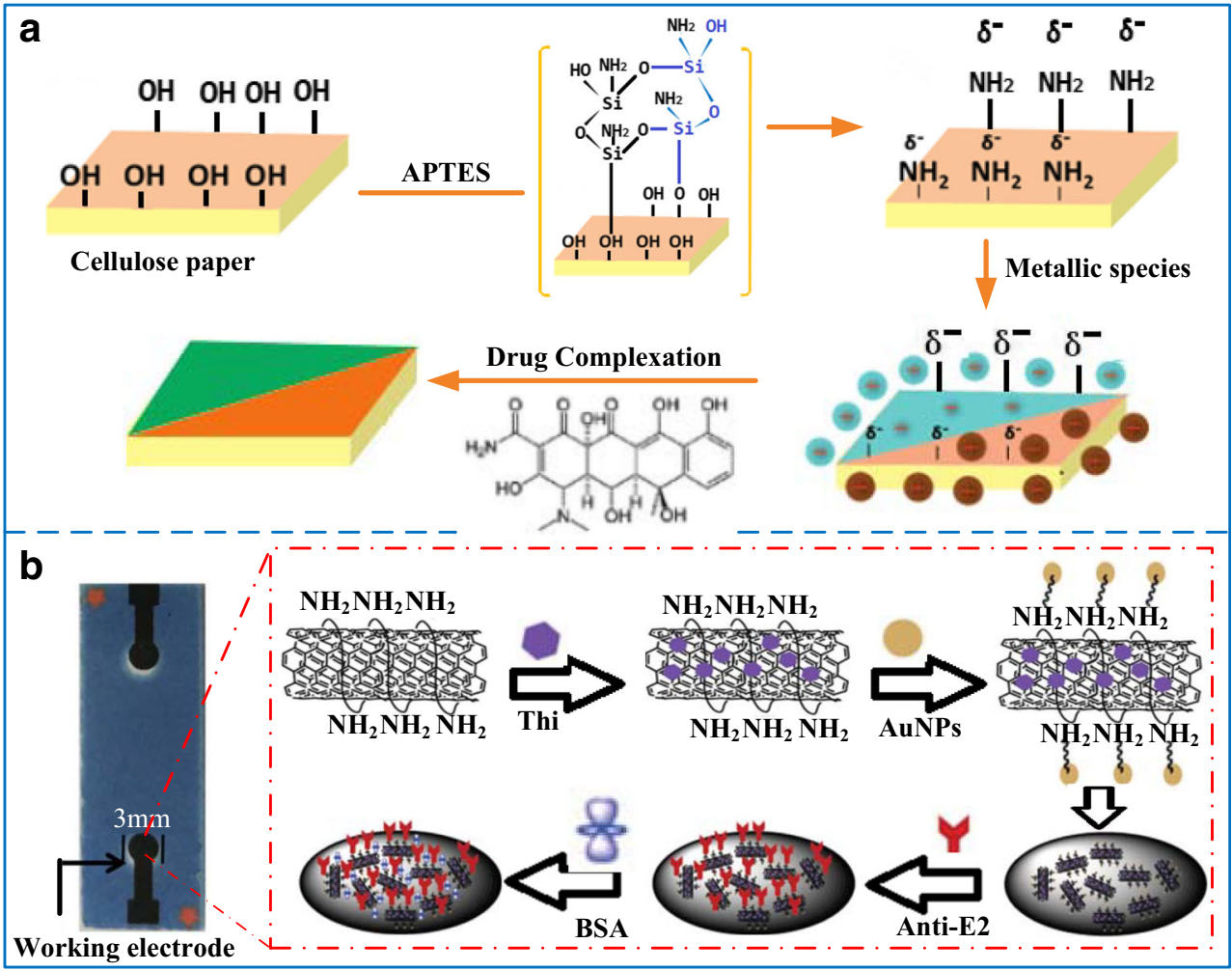


detector to combine with this device. However, the synthesis and functionalization of MWCNTs/THI/AuNPs is time consuming and complex.

\section{Ion/other chemical molecule detection}

Heavy metals and toxic chemical molecules in drinking water threaten human health worldwide. Various novel paper-based devices have been fabricated and used for ion/chemical molecule detection. However, the low detection sensitivity of these devices is still a challenge for their further applications.

To handle this problem, various modification approaches have been utilized to change the surface chemical groups and hydrophilic/hydrophobic features of paper for ion/chemical molecule detection. For instance, APTMS, 3triethoxysilylpropyl succinic anhydride (TESPSA) and mercaptopropyl trimethoxysilane (MPTMS) were modified on Whatman ${ }^{\circledR}$ chromatography paper by depositing vaporization for achieving multiplex detection of heavy metals (Fig. 11) [134]. The modification process immobilized amine groups, carboxyl groups and thiol groups on the surface of chromatography paper by condensation reactions. Three chromogenic reagents that reacted strongly with $\mathrm{Ni}(\mathrm{II}), \mathrm{Cr}(\mathrm{VI})$ and $\mathrm{Hg}$ (II) were covalently coupled to these functional groups, leading to color change of paper based on metal complexation reaction. The detection limits of the prepared devices are
$0.24 \mathrm{ppm}$ for $\mathrm{Ni}(\mathrm{II}), 0.18 \mathrm{ppm}$ for $\mathrm{Cr}(\mathrm{VI})$ and $0.19 \mathrm{ppm}$ for $\mathrm{Hg}(\mathrm{II})$, respectively. It provides a simple and reliable analytical tool for POCT in low-resource settings. However, the uniformity of the modification approach need be further improved. In addition, filter paper modified with chitosan was also used to fabricate a colorimetric test strip for detection of mercury (Hg(II)) (Fig. 12) [29]. The paper test strip was fabricated by incorporating silver-doped CdS dots capped with mercaptoacetic into chitosan-coated filter paper, which can make a visualized color change from yellow to deep brown when $\mathrm{Hg}(\mathrm{II})$ ions were captured by the mercaptoacetic acid on CdSAg. The modification process enhanced the stability of CdSAg QDs immobilization and accelerated the process of colored adduct formation. The detection limit of the paper test strip for $\mathrm{Hg}$ (II) was $124 \mu \mathrm{M}$. It is a rapid and portable diagnostic, making it in real-time detection. However, this modification process is influenced by the chitosan concentration. Moreover, BSA was utilized to tune the wettability of Whatman ${ }^{\circledR}$ chromatography paper and the BSA-modified chromatography paper was used as a substrate of patterned paper assay by simple writing and stamping patterns on its surface (Fig. 13) [135]. This modification technology achieved the position control and spatial confinement of assay regions via the low solubility of the colored product. And the fabricated paper assay was successfully used to perform multitarget detections of $\mathrm{Cu}^{2+}$ and $\mathrm{Ni}^{2+}$ based on the precipitation
Fig. 11 Paper modification approaches for ion/other chemical molecule detection. Whatman ${ }^{\circledR}$ chromatography paper modified with APTMS, TESPSA and MPTMS for Ni(II), $\mathrm{Cr}(\mathrm{II})$ and $\mathrm{Hg}(\mathrm{II})$, respectively [134]

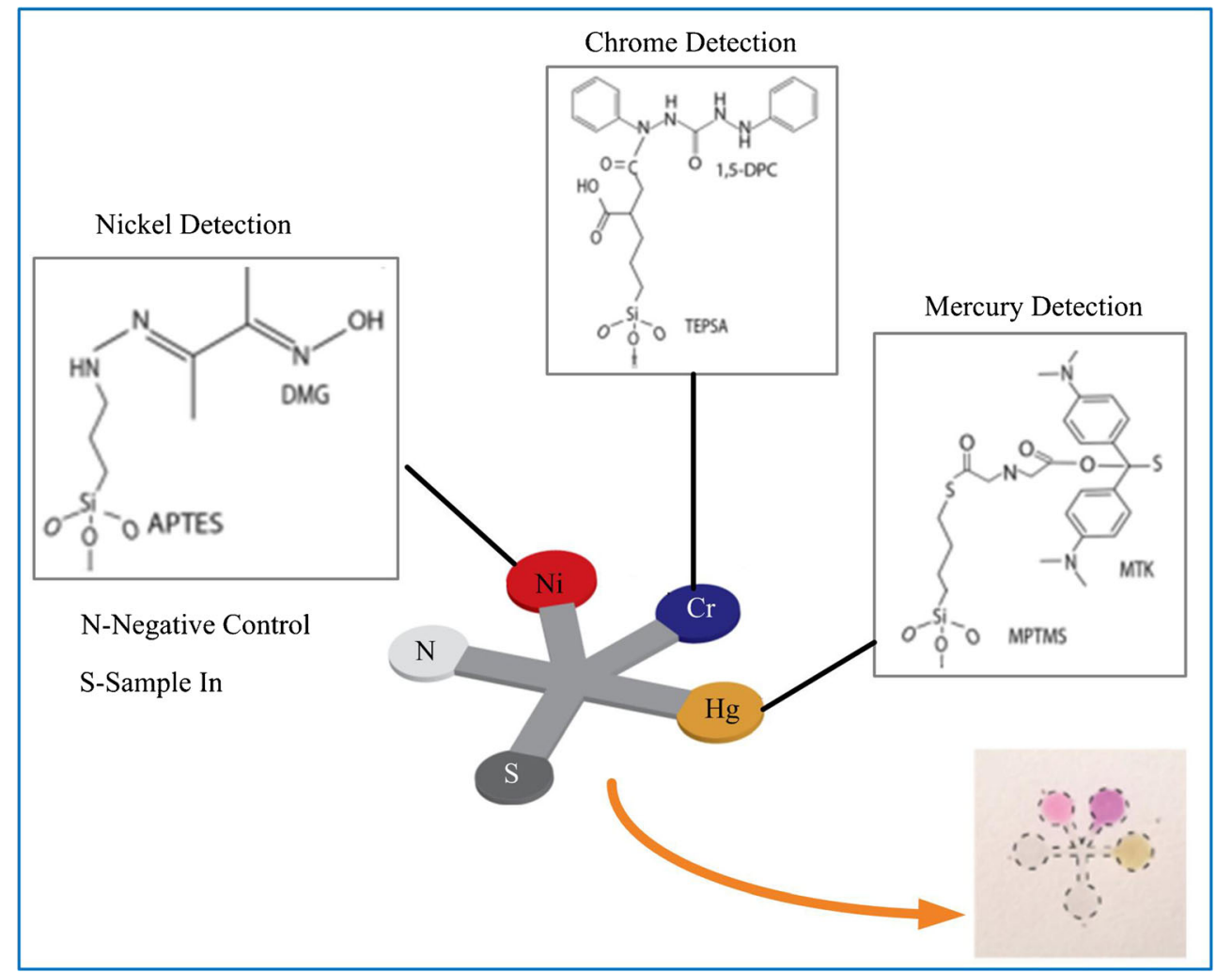


Fig. 12 Paper modification approaches for ion/other chemical molecule detection. Filter paper modified with chitosan has been used to fabricate a colorimetric test strip for the detection of mercury $(\mathrm{Hg}(\mathrm{II}))[29]$

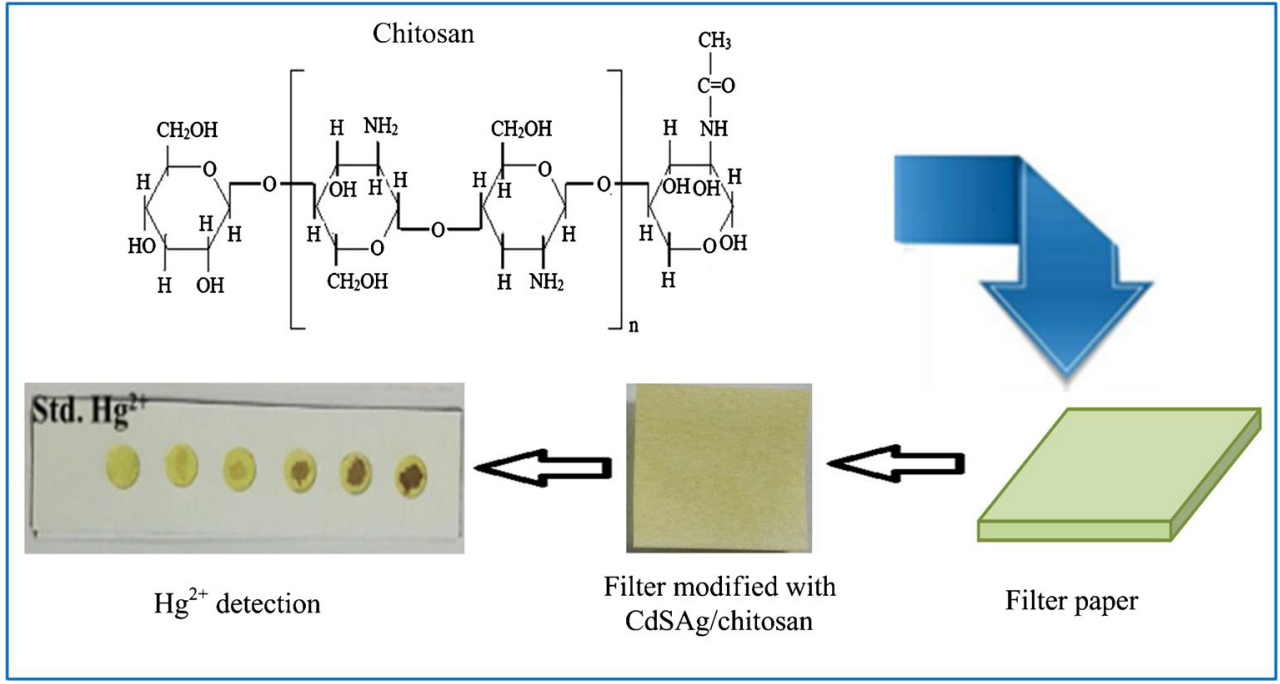

reaction. It provides a portable diagnosis tool for POCT. However, this modification process is affected by the reaction temperature.

In addition, the wax patterned filter paper modified with cobalt(II) phthalocyanine/ionic liquid/graphene composite $(\mathrm{CoPc} / \mathrm{IL} / \mathrm{G})$ was used to fabricate an electrochemical paperbased assay for glucose detection (Fig. 14) [136]. The paperbased assay was fabricated by printing wax, $\mathrm{CoPc} / \mathrm{IL} / \mathrm{G}$ composite solution onto filter paper to prepare reaction regions and electrodes and depended on electronic signal to achieve detection. The modification process conferred the paper-based electrode excellent conductivity and fast electron transfer kinetics compared to those of the unmodified paper-based electrodes by enhancing the specific surface area of the paper-based material. The detection limit of glucose of this assay is $0.67 \mu \mathrm{M}$, and the linear dynamic ranges are $0.01 \mu \mathrm{M}-1.3 \mu \mathrm{M}$ and $1.3 \mu \mathrm{M}-5.0 \mu \mathrm{M}$ for low and high concentrations of glucose. To achieve the reality of POCT, the portable electrochemical detection device will be further developed. However, this modification technology requires multistep modification.

Based on the above summary, various chemical reagents, including CMC, PAMAM dendrimers, FF, chitosan, SBA-15, polysiloxanes, acrylic polymers, 1,4 phenylenediisothiocyanate, wax, PDMS, APTMS/TESPSA/ MPTMS, APTES, CoPc/IL/G, MWCNTs/THI/AuNPs and BSA, have all been used to modify different types of papers to improve their detection efficiencies of nucleic acids, proteins, drugs and ions/other chemical molecules, respectively. Among these reagents, CMC, PAMAM dendrimers, 1, 4phenylenediisothiocyanate and APTMS/TESPSA/MPTMS can change the chemical groups on the paper surface. Polysiloxanes can change the hydrophilic/hydrophobic nature of thread. Chitosan, FF and BSA can change the wet strength of paper. Wax, PDMS and acrylic polymers can penetrate into paper to form hydrophobic barriers. CoPc/IL/G and MWCNTs/THI/AuNPs can improve the specific surface area
Fig. 13 Paper modification approaches for ion/other chemical molecule detection. Whatman ${ }^{\circledR}$ chromatography paper modified with BSA for multi-targets detection of $\mathrm{Cu}^{2+}$ and $\mathrm{Ni}^{2+}[135]$

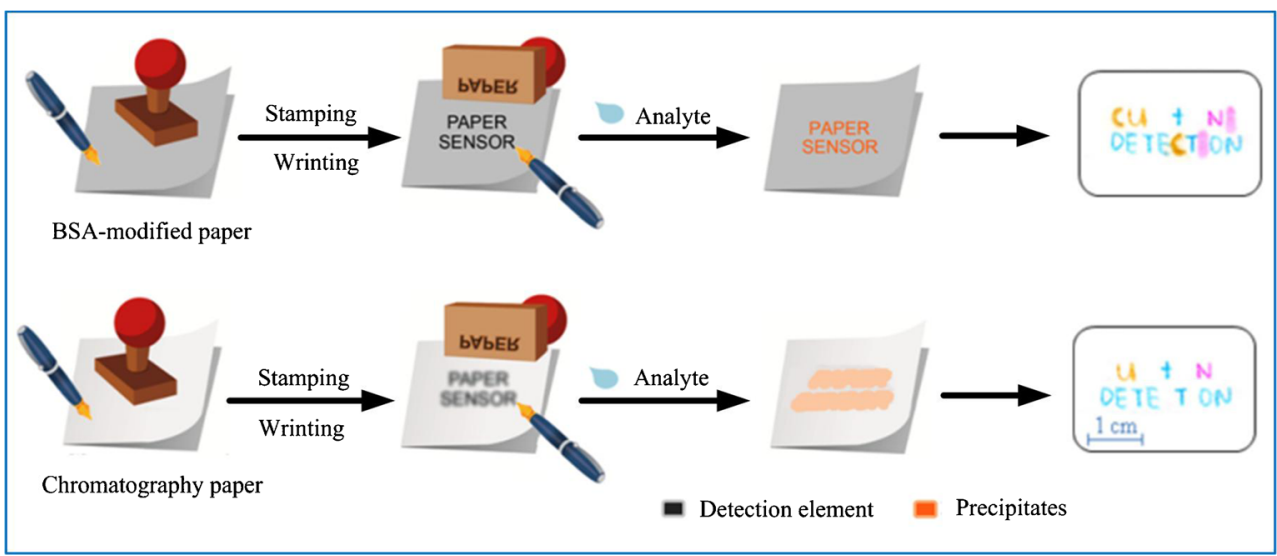


Fig. 14 Paper modification approaches for ion/other chemical molecule detection. Filter paper after wax patterned modified with $\mathrm{CoPc} / \mathrm{IL} / \mathrm{G}$ for the glucose detection [136]

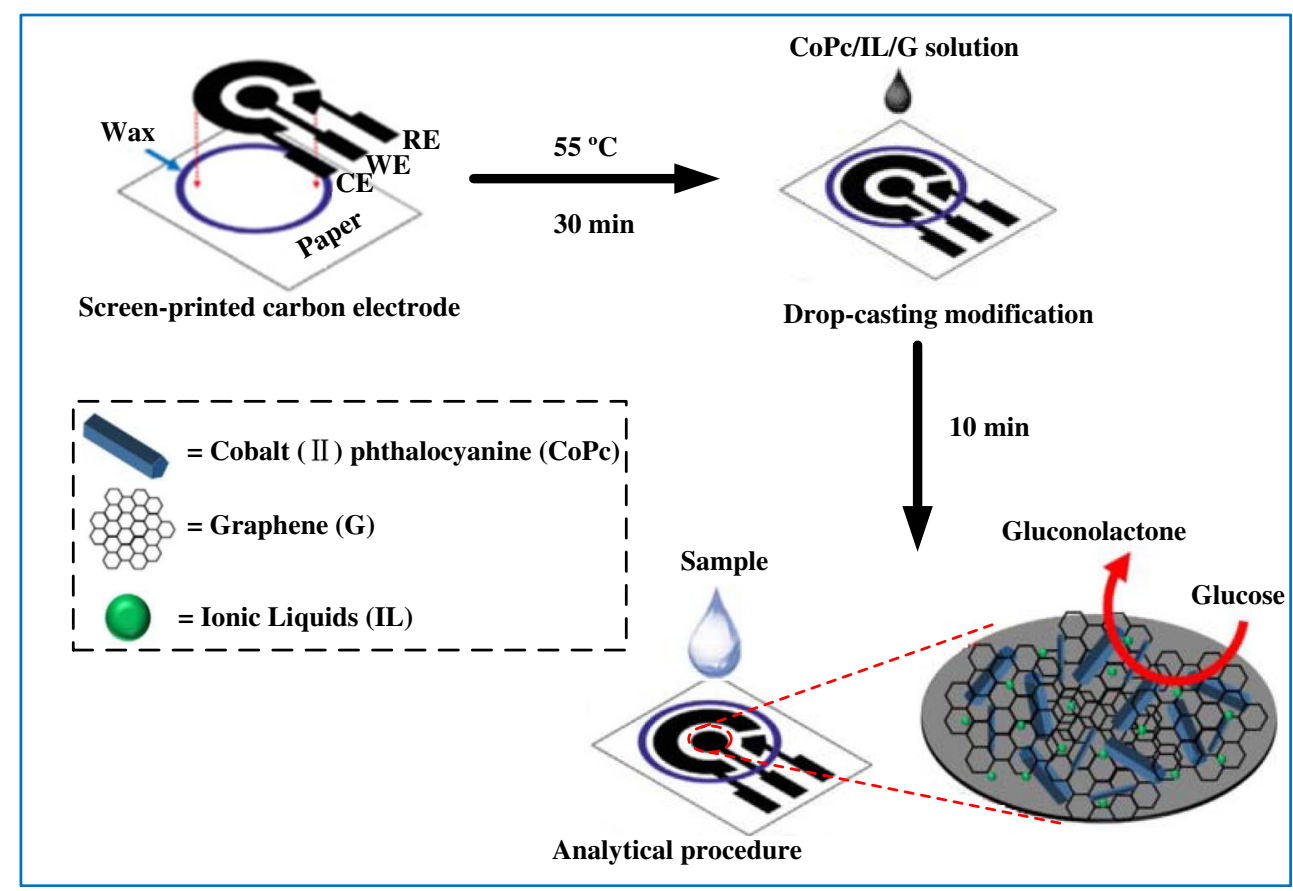

of paper. SBA-15 was used to modify paper by changing the specific surface area and altering the surface chemical groups on the paper. However, to alter other features of paper (e.g., porosity and pore size), the types of chemical reagents for modification are still limited.

\section{Conclusion and future perspectives}

Papers with different physicochemical properties have been utilized to fabricate various paper-based devices and used for sample pretreatment and sample detection in the POCT field. Considering that the performance of the paper-based devices with using the unmodified papers is still not satisfactory, many modification approaches have been utilized to tune the physicochemical features of paper materials, such as chemical groups, surface charge, hydrophilicity/hydrophobicity, wet strength and hydrophobic patterns/barriers. However, even the most common modification approaches are also associated with some limitations and cannot be widely used for batch preparation of paper-based devices. For example, experimental results often lack theoretical verification, such as the theory of fluid flow and the mass transfer/bioreactions inside the paper. Thus the mathematical models should be developed to analyze the convection-diffusion-reaction process in paper before and after modification [14, 21, 139, 140]. And the model results should be compared with the experimental results. In addition, to further understand the regulatory mechanism of modification reagents on paper, the physicochemical properties of paper before and after modification need be measured [141]. Furthermore, most chemical modification approaches are carried out on the commercial papers, resulting in the poor uniformity of structure due to artificial operation [29]. To improve the poor uniformity of structure, new paper modification approaches based on the papermaking process, such as addition of chemical reagents during the pulping process [142], can be used to produce special functional papers. Finally, hydrophobic patterning and barrier modification approaches will be further developed for integration with paperbased electronic chips [143].

Further effort will focus on developing the novel cellulosebased composite materials with programmable and tunable physicochemical properties for the fabrication of paperbased devices. To realize the practical use of paper-based devices and LFAs in POCT, the existing mature modification approaches (e.g., wax-based modification approach [144, 145] and chitosan-based modification approach [12, 109]) will step into the market. Furthermore, to fabricate paperbased integrated electronic chips, single paper material with multifunctional areas will be developed using different modification approaches. To integrate the extra criterion of $\mathrm{R}$ (realtime connectivity) and $\mathrm{E}$ (ease of specimen collection and environmental friendliness) into the ASSURED of POCT device and then create a new standard of REASSURED additionally, POCT devices should incorporate environmentalfriendly modification reagents (e.g., chitosan [146]) to change the physiochemical feature of paper materials. Finally, paperbased modification approaches will play a greater role in POCT. For example, novel properties paper will be used for POCT detection (e.g., polydiacetylene-based paper assay shows chromatic properties and then it can be used for naked-eye detection of pandemic influenza a virus [147]). 
Composites materials can be utilized to increase the features of papers (e.g., graphene oxide/thionine/gold nanoparticles nanocomposites have been used for increase the adsorption ability of biomolecules on paper for cancer antigen 125 detection [148]).

Acknowledgements This work was supported by the National Natural Science Foundation of China $(21808132,31700510,21774071)$, the China Postdoctoral Science Foundation (2018M633525), the Project of Shaanxi Provincial Education department (18JK0096), the Natural Science Basic Research Plan of Shaanxi Province (2019JQ-517), the Opening Project of National Experimental Teaching Demonstration Center of Light Chemical Engineering (2018QGSJ02-10), the Highlevel Foreign Experts Project (GD20186100425), the Natural Science Research Foundation of Shaanxi University of Science \& Technology (2017BJ-35), "Biomass Chemistry and Materials" Academician Workstation Project in SUST (134090002), Key Scientific Research Group of Shaanxi Province (2017KCT-02) and the Key Program for Science and Technology Innovative Research Team in Shaanxi Province of China (2017KCT-22).

Compliance with ethical standards The author(s) declare that they have no competing interests

\section{References}

1. Land KJ, Boeras DI, Chen XS, Ramsay AR, Peeling RW (2019) REASSURED diagnostics to inform disease control strategies, strengthen health systems and improve patient outcomes. Nat Microbiol 4(1):46-54. https://doi.org/10.1038/s41564-018-0295-

2. Hudson K (2005) Get bedside results with point of care testing. Nurs Manag 36:45-46. https://doi.org/10.1097/00006247200501000-00012

3. Gootenberg JS, Abudayyeh OO, Zhang F (2018) Multiplexed and portable nucleic acid detection platform with Cas13, Cas12a, and Csm6. Science 360(6387):439-444. https://doi.org/10.1126/ science.aaq0179

4. Tapper EB, Parikh ND, Waljee AK, Volk M, Carlozzi NE, Lok AS (2018) Diagnosis of minimal hepatic encephalopathy: a systematic review of point-of-care diagnostic tests. Am J Gastroenterol 113(4):1-10. https://doi.org/10.1038/ajg.2018.6

5. Reddy B, Hassan U, Seymour C, Angus DC, Isbell TS, White K, Weir W, Yeh L, Vincent A, Bashir R (2018) Point-of-care sensors for the management of sepsis. Nat Biomedical Eng 2(9):640-648. https://doi.org/10.1038/s41551-018-0288-9

6. Yang MZ, Zhang W, Yang JC, Hu BF, Cao FJ, Zheng WS, Chen YP, Jiang XY (2017) Skiving stacked sheets of paper into test paper for rapid and multiplexed assay. Sci Adv 3(12):eaao4862. https://doi.org/10.1126/sciadv.aao4862

7. Lin BQ, Guan ZC, Song YL, Song E, Lu ZF, Liu D, An Y, Zhu Z, Zhou LJ, Yang CY (2018) Lateral flow assay with pressure meter readout for rapid point-of-care detection of disease-associated protein. Lab Chip 18(6):965-970. https://doi.org/10.1039/ c81c00010g

8. Brangel P, Sobarzo A, Parolo C, Miller BS, Howes PD, Gelkop S, Lutwama JJ, Dye JM, McKendry RA, Lobel L, Stevens MM (2018) A serological point-of-care test for the detection of igg antibodies against ebola virus in human survivors. ACS Nano 12(1):63-73. https://doi.org/10.1021/acsnano.7b07021

9. Bonacchini GE, Bossio C, Greco F, Mattoli V, Kim YH, Lanzani G, Caironi M (2018) Tattoo-paper transfer as a versatile platform for all-printed organic edible electronics. Adv Mater 30(14): e1706091. https://doi.org/10.1002/adma.201706091

10. Nilghaz A, Guan LY, Tan WR, Shen W (2016) Advances of paperbased microfluidics for diagnostics - the original motivation and current status. ACS Sensors 1(12):1382-1393. https://doi.org/10. 1021/acssensors.6b00578

11. Luo L, Li X, Crooks RM (2014) Low-voltage origami-paperbased electrophoretic device for rapid protein separation. Anal Chem 86(24):12390-12397. https://doi.org/10.1021/ac503976c

12. Gan W, Gu Y, Han J, Li CX, Sun J, Liu P (2017) Chitosanmodified filter paper for nucleic acid extraction and "in Situ PCR" on a thermoplastic microchip. Anal Chem 89(6):3568 3575. https://doi.org/10.1021/acs.analchem.6b04882

13. Tiwari S, Vinchurkar M, Rao VR, Garnier G (2017) Zinc oxide nanorods functionalized paper for protein preconcentration in biodiagnostics. Sci Rep 7:43905. https://doi.org/10.1038/ srep43905

14. Choi JR, Hu J, Feng S, Wan Abas WA, Pingguan-Murphy B, Xu F (2016) Sensitive biomolecule detection in lateral flow assay with a portable temperature-humidity control device. Biosens Bioelectron 79:98-107. https://doi.org/10.1016/j.bios.2015.12. 005

15. Tang RH, Yang H, Gong Y, You ML, Liu Z, Choi JR, Wen T, Qu ZG, Mei QB, Xu F (2017) A fully disposable and integrated paper-based device for nucleic acid extraction, amplification and detection. Lab Chip 17(7):1270-1279. https://doi.org/10.1039/ c6lc01586g

16. Lopez Marzo AM, Pons J, Blake DA, Merkoci A (2013) Allintegrated and highly sensitive paper based device with sample treatment platform for $\mathrm{Cd} 2+$ immunodetection in drinking/tap waters. Anal Chem 85(7):3532-3538. https://doi.org/10.1021/ ac3034536

17. Yang XX, Forouzan O, Brown TP, Shevkoplyas SS (2012) Integrated separation of blood plasma from whole blood for microfluidic paper-based analytical devices. Lab Chip 12:274 280. https://doi.org/10.1039/c1lc20803a

18. McFall SM, Wagner RL, Jangam SR, Yamada DH, Hardie D, Kelso DM (2015) A simple and rapid DNA extraction method from whole blood for highly sensitive detection and quantitation of HIV-1 proviral DNA by real-time PCR. J Virol Methods 214: 37-42. https://doi.org/10.1016/j.jviromet.2015.01.005

19. Zhang Y, Rojas OJ (2017) Immunosensors for C-reactive protein based on ultrathin films of carboxylated cellulose nanofibrils. Biomacromolecules 18(2):526-534. https://doi.org/10.1021/acs. biomac.6b01681

20. Liu J, He Y, Chen S, Ma M, Yao S, Chen B (2017) New ureamodified paper substrate for enhanced analytical performance of negative ion mode paper spray mass spectrometry. Talanta 166: 306-314. https://doi.org/10.1016/j.talanta.2017.01.076

21. Tang RH, Yang H, Choi JR, Gong Y, Hu J, Wen T, Li XJ, Xu B, Mei QB, Xu F (2017) Paper-based device with on-chip reagent storage for rapid extraction of DNA from biological samples. Microchim Acta 184(7):2141-2150. https://doi.org/10.1007/ s00604-017-2225-0

22. Songjaroen T, Dungchai W, Chailapakul O, Henry CS, Laiwattanapaisal W (2012) Blood separation on microfluidic paper-based analytical devices. Lab Chip 12(18):3392-3398. https://doi.org/10.1039/c21c21299d

23. Liu C, Mauk M, Gross R, Bushman FD, Edelstein PH, Collman RG, Bau HH (2013) Membrane-based, sedimentation-assisted plasma separator for point-of-care applications. Anal Chem 85(21):10463-10470. https://doi.org/10.1021/ac402459h

24. Mosley GL, Pereira DY, Han Y, Lee SY, Wu CM, Wu BM, Kamei DT (2017) Improved lateral-flow immunoassays for chlamydia and immunoglobulin $\mathrm{M}$ by sequential rehydration of two-phase system components within a paper-based diagnostic. Microchim 
Acta 184(10):4055-4064. https://doi.org/10.1007/s00604-0172434-6

25. Lu X, Mei T, Guo Q, Zhou W, Li X, Chen J, Zhou X, Sun N, Fang $Z$ (2018) Improved performance of lateral flow immunoassays for alpha-fetoprotein and vanillin by using silica shell-stabilized gold nanoparticles. Mikrochimica Acta 186(1):2. https://doi.org/10. 1007/s00604-018-3107-9

26. Derikvand F, Yin DT, Barrett R, Brumer H (2016) CelluloseBased Biosensors for Esterase Detection. Anal Chem 88(6): 2989-2993. https://doi.org/10.1021/acs.analchem.5b04661

27. Yan JX, Yan M, Ge L, Ge SG, Yu JH (2014) An origami electrochemiluminescence immunosensor based on gold/ graphene for specific, sensitive point-of-care testing of carcinoembryonic antigen. Sensors Actuators B Chem 193:247254. https://doi.org/10.1016/j.snb.2013.11.107

28. Li ZD, Li F, Xing Y, Liu Z, You ML, Li YC, Wen T, Qu ZG, Li XL, Xu F (2017) Pen-on-paper strategy for point-of-care testing: rapid prototyping of fully written microfluidic biosensor. Biosens Bioelectron 98:478-485. https://doi.org/10.1016/j.bios.2017.06. 061

29. Butwong N, Kunthadong P, Soisungnoen P, Chotichayapong C, Srijaranai S, Luong JHT (2018) Silver-doped CdS quantum dots incorporated into chitosan-coated cellulose as a colorimetric paper test stripe for mercury. Mikrochimica Acta 185(2):126. https://doi. org/10.1007/s00604-018-2671-3

30. Anfossi L, Di Nardo F, Cavalera S, Giovannoli C, Spano G, Speranskaya ES, Goryacheva IY, Baggiani C (2018) A lateral flow immunoassay for straightforward determination of fumonisin mycotoxins based on the quenching of the fluorescence of CdSe/ $\mathrm{ZnS}$ quantum dots by gold and silver nanoparticles. Mikrochimica Acta 185(2):94. https://doi.org/10.1007/s00604-017-2642-0

31. Sheng W, Chang Q, Shi Y, Duan W, Zhang Y, Wang S (2018) Visual and fluorometric lateral flow immunoassay combined with a dual-functional test mode for rapid determination of tetracycline antibiotics. Mikrochimica Acta 185(9):404. https://doi.org/10. 1007/s00604-018-2945-9

32. Sheng W, Li S, Liu Y, Wang J, Zhang Y, Wang S (2017) Visual and rapid lateral flow immunochromatographic assay for enrofloxacin using dyed polymer microspheres and quantum dots. Microchim Acta 184(11):4313-4321. https://doi.org/10.1007/ s00604-017-2474-y

33. Nutthaya Butwong PK, Soisungnoen P, Chotichiayapong C, Srijaranai S, Luong JHT (2018) Silver-doped CdS quantum dots incorporated into chitosan-coated cellulose as a colorimetric paper test stripe for mercury. Microchim Acta 185:126-135

34. Magiati M, Sevastou A, Kalogianni DP (2018) A fluorometric lateral flow assay for visual detection of nucleic acids using a digital camera readout. Mikrochimica Acta 185(6):314. https:// doi.org/10.1007/s00604-018-2856-9

35. Boonkaew S, Chaiyo S, Jampasa S, Rengpipat S, Siangproh W, Chailapakul O (2019) An origami paper-based electrochemical immunoassay for the C-reactive protein using a screen-printed carbon electrode modified with graphene and gold nanoparticles. Mikrochimica Acta 186(3):153. https://doi.org/10.1007/s00604019-3245-8

36. Taranova NA, Urusov AE, Sadykhov EG, Zherdev AV, Dzantiev BB (2017) Bifunctional gold nanoparticles as an agglomerationenhancing tool for highly sensitive lateral flow tests: a case study with procalcitonin. Microchim Acta 184(10):4189-4195. https:// doi.org/10.1007/s00604-017-2355-4

37. Wang W, Liu L, Song S, Xu L, Kuang H, Zhu J, Xu C (2016) Identification and quantification of eight Listeria monocytogene serotypes from Listeria spp. using a gold nanoparticle-based lateral flow assay. Microchim Acta 184(3):715-724. https://doi.org/10. 1007/s00604-016-2028-8
38. Ruppert C, Phogat N, Laufer S, Kohl M, Deigner HP (2019) A smartphone readout system for gold nanoparticle-based lateral flow assays: application to monitoring of digoxigenin. Mikrochimica Acta 186(2):119. https://doi.org/10.1007/s00604018-3195-6

39. Shi QQ, Huang J, Sun YN, Deng RG, Teng M, Li QM, Yang YY, Hu XF, Zhang ZJ, Zhang GP (2018) A SERS-based multiple immuno-nanoprobe for ultrasensitive detection of neomycin and quinolone antibiotics via a lateral flow assay. Microchem J 185(2): 84-92. https://doi.org/10.1007/s00604-017-2556-x

40. Yao L, Teng J, Qu H, Zhu M, Zheng L, Xue F, Chen W (2016) Paper matrix based array for rapid and sensitive optical detection of mercury ions using silver enhancement. Microchim Acta 184(2):569-576. https://doi.org/10.1007/s00604-016-2052-8

41. Li S, Wang J, Sheng W, Wen W, Gu Y, Wang S (2018) Fluorometric lateral flow immunochromatographic zearalenone assay by exploiting a quencher system composed of carbon dots and silver nanoparticles. Microchim Acta 185(8). https://doi.org/ 10.1007/s00604-018-2916-1

42. Urusov AE, Gubaidullina MK, Petrakova AV, Zherdev AV, Dzantiev BB (2018) A new kind of highly sensitive competitive lateral flow immunoassay displaying direct analyte-signal dependence. Application to the determination of the mycotoxin deoxynivalenol. Mikrochimica Acta 185(1):29. https://doi.org/ 10.1007/s00604-017-2576-6

43. Panferov VG, Safenkova IV, Varitsev YA, Zherdev AV, Dzantiev BB (2017) Enhancement of lateral flow immunoassay by alkaline phosphatase: a simple and highly sensitive test for potato virus $\mathrm{X}$. Mikrochimica Acta 185(1):25. https://doi.org/10.1007/s00604017-2595-3

44. Cheng T, Zhang Y, Liu X, Zhang X, Zhang H (2017) A filter paper coated with phenylboronic acid-modified mesoporous silica for enrichment of intracellular nucleosides prior to their quantitation by HPLC. Microchim Acta 184(10):4007-4013. https://doi.org/ 10.1007/s00604-017-2423-9

45. Pungjunun K, Chaiyo S, Jantrahong I, Nantaphol S, Siangproh W, Chailapakul O (2018) Anodic stripping voltammetric determination of total arsenic using a gold nanoparticle-modified borondoped diamond electrode on a paper-based device. Mikrochimica Acta 185(7):324. https://doi.org/10.1007/s00604018-2821-7

46. Faham S, Khayatian G, Golmohammadi H, Ghavami R (2018) A paper-based optical probe for chromium by using gold nanoparticles modified with 2,2'-thiodiacetic acid and smartphone camera readout. Mikrochimica Acta 185(8):374. https://doi.org/10.1007/ s00604-018-2875-6

47. Fu X, Chu Y, Zhao K, Li J, Deng A (2017) Ultrasensitive detection of the $\beta$-adrenergic agonist brombuterol by a SERS-based lateral flow immunochromatographic assay using flower-like gold-silver core-shell nanoparticles. Microchim Acta 184(6):1711-1719. https://doi.org/10.1007/s00604-017-2178-3

48. Darabdhara G, Boruah PK, Das MR (2018) Colorimetric determination of glucose in solution and via the use of a paper strip by exploiting the peroxidase and oxidase mimicking activity of bimetallic $\mathrm{Cu}-\mathrm{Pd}$ nanoparticles deposited on reduced graphene oxide, graphitic carbon nitride, or MoS2 nanosheets. Mikrochimica Acta 186(1):13. https://doi.org/10.1007/s00604-018-3112-Z

49. Zhang Y, Liao Z, Liu Y, Wan Y, Chang J, Wang H (2017) Flow cytometric immunoassay for aflatoxin B1 using magnetic microspheres encoded with upconverting fluorescent nanocrystals. Microchim Acta 184(5):1471-1479. https://doi.org/10.1007/ s00604-017-2116-4

50. Ortiz-Gomez I, Salinas-Castillo A, Garcia AG, Alvarez-Bermejo JA, de Orbe-Paya I, Rodriguez-Dieguez A, Capitan-Vallvey LF (2017) Microfluidic paper-based device for colorimetric determination of glucose based on a metal-organic framework acting as 
peroxidase mimetic. Mikrochimica Acta 185(1):47. https://doi. org/10.1007/s00604-017-2575-7

51. Wang R, Zhang W, Wang P, Su X (2018) A paper-based competitive lateral flow immunoassay for multi beta-agonist residues by using a single monoclonal antibody labelled with red fluorescent nanoparticles. Mikrochimica Acta 185(3):191. https://doi.org/10. 1007/s00604-018-2730-9

52. Yang Y, Ozsoz M, Liu G (2017) Gold nanocage-based lateral flow immunoassay for immunoglobulin G. Mikrochimica Acta 184(7): 2023-2029. https://doi.org/10.1007/s00604-017-2176-5

53. Tao Y, Yang J, Chen L, Huang Y, Qiu B, Guo L, Lin Z (2018) Dialysis assisted ligand exchange on gold nanorods: Amplification of the performance of a lateral flow immunoassay for E. coli O157:H7. Mikrochimica Acta 185(7):350. https://doi. org/10.1007/s00604-018-2897-0

54. Weng X, Neethirajan S (2017) Aptamer-based fluorometric determination of norovirus using a paper-based microfluidic device. Microchim Acta 184(11):4545-4552. https://doi.org/10.1007/ s00604-017-2467-x

55. Wang Y, Wang Y, Li D, Xu J, Ye C (2018) Detection of nucleic acids and elimination of carryover contamination by using loopmediated isothermal amplification and antarctic thermal sensitive uracil-DNA-glycosylase in a lateral flow biosensor: application to the detection of Streptococcus pneumoniae. Microchim Acta 185(4). https://doi.org/10.1007/s00604-018-2723-8

56. Hu J, Wang SQ, Wang L, Li F, Pingguan-Murphy B, Lu TJ, Xu F (2014) Advances in paper-based point-of-care diagnostics. Biosens Bioelectron 54:585-597. https://doi.org/10.1016/j.bios. 2013.10.075

57. Gong MM, Sinton D (2017) Turning the page: advancing paperbased microfluidics for broad diagnostic application. Chem Rev 117(12):8447-8480. https://doi.org/10.1021/acs.chemrev. $7 \mathrm{~b} 00024$

58. Yamada K, Henares TG, Suzuki K, Citterio D (2015) Paper-based inkjet-printed microfluidic analytical device. Angew Chem Int Ed 54:2-19. https://doi.org/10.1002/anie.201411508

59. Xu Y, Liu M, Kong N, Liu J (2016) Lab-on-paper micro- and nano-analytical devices: Fabrication, modification, detection and emerging applications. Microchim Acta 183(5):1521-1542. https://doi.org/10.1007/s00604-016-1841-4

60. Martinez AW, Phillips ST, Butte MJ, Whitesides GM (2007) Patterned paper as a platform for inexpensive, low-volume, portable bioassays. Angew Chem 46(8):1318-1320. https://doi.org/ 10.1002/anie.200603817

61. Sahin HT, Arslan MB (2008) A study on physical and chemical properties of cellulose paper immersed in various solvent mixtures. Int J Mol Sci 9:78-88. https://doi.org/10.3390/ijms9010078

62. Shen J, Song ZQ, Qian XR, Liu WX (2009) Modification of papermaking grade fillers: a brief review. BioResources 4(3): 1190-1209. https://doi.org/10.1007/s00226-008-0200-y

63. Elizalde E, Urteaga R, Berli CLA (2016) Precise capillary flow for paper-based viscometry. Microfluid Nanofluid 20(10). https://doi. org/10.1007/s10404-016-1800-8

64. Tang RH, Yang H, Gong Y, Liu Z, Li X, Wen T, Qu Z, Zhang S, Mei QB, Xu F (2017) Improved analytical sensitivity of lateral flow assay using sponge for HBV nucleic acid detection. Sci Rep 7(1):1360. https://doi.org/10.1038/s41598-017-01558-x

65. Jeong S-G, Kim J, Jin SH, Park K-S, Lee C-S (2016) Flow control in paper-based microfluidic device for automatic multistep assays: a focused minireview. Korean J Chem Eng 33(10):2761-2770. https://doi.org/10.1007/s11814-016-0161-z

66. Ballerini DR, Li X, Shen W (2012) Patterned paper and alternative materials as substrates for low-cost microfluidic diagnostics. Microfluid Nanofluid 13(5):769-787. https://doi.org/10.1007/ s10404-012-0999-2
67. Mohite BV, Patil SV (2014) Bacterial cellulose of Gluconoacetobacter hansenii as a potential bioadsorption agent for its green environment applications. J Biomater Sci Polym Ed 25(18):2053-2065. https://doi.org/10.1080/09205063.2014. 970063

68. Wu Y, Luo H, Wang H, Zhang L, Liu P, Feng L (2014) Fast adsorption of nickel ions by porous graphene oxide/sawdust composite and reuse for phenol degradation from aqueous solutions. J Colloid Interface Sci 436:90-98. https://doi.org/10.1016/j.jcis. 2014.08.068

69. Wei X, Huang T, Yang JH, Zhang N, Wang Y, Zhou ZW (2017) Green synthesis of hybrid graphene oxide/microcrystalline cellulose aerogels and their use as superabsorbents. J Hazard Mater 335:28-38. https://doi.org/10.1016/j.jhazmat.2017.04.030

70. Zhou Y, Min Y, Qiao H, Huang Q, Wang E, Ma T (2015) Improved removal of malachite green from aqueous solution using chemically modified cellulose by anhydride. Int J Biol Macromol 74:271-277. https://doi.org/10.1016/j.ijbiomac.2014. 12.020

71. Zhang Y, Liu Y, Wang X, Sun Z, Ma J, Wu T, Xing F, Gao J (2014) Porous graphene oxide/carboxymethyl cellulose monoliths, with high metal ion adsorption. Carbohydr Polym 101:392-400. https://doi.org/10.1016/j.carbpol.2013.09.066

72. Li Q, Sun J, Ren T, Guo L, Yang Z, Yang Q, Chen H (2018) Adsorption mechanism of 2,4-dichlorophenoxyacetic acid onto nitric-acid-modified activated carbon fiber. Environ Technol 39(7):895-906. https://doi.org/10.1080/09593330.2017.1316318

73. Deng H, Ning J, Wang X (2016) Amino-functionalized cotton fiber for enhanced adsorption of active brilliant red X-3B from aqueous solution. Microsc Res Tech 79(12):1200-1207. https:// doi.org/10.1002/jemt.22778

74. Li J, Liao XP, Zhang QX, Shi B (2013) Adsorption and separation of proteins by collagen fiber adsorbent. J Chromatogr B Anal Technol Biomed Life Sci 928:131-138. https://doi.org/10.1016/j. jchromb.2013.03.031

75. Lu T, Chen X, Shi Q, Wang Y, Zhang P, Jing X (2008) The immobilization of proteins on biodegradable fibers via biotinstreptavidin bridges. Acta Biomater 4(6):1770-1777. https://doi. org/10.1016/j.actbio.2008.05.006

76. Serafica GC, Pimbley J, Belfort G (1994) Protein fractionation using fast flow immobilized metal chelate affinity membranes. Biotechnol Bioeng 43:21-36. https://doi.org/10.1002/bit. 260430105

77. Lowa SC, Shaimi R, Thandaithabany Y, Lim JK, Ahmad AL, Ismail A (2013) Electrophoretic interactions between nitrocellulose membranes and proteins: Biointerface analysis and protein adhesion properties. Colloids Surf B: Biointerfaces 110:248253. https://doi.org/10.1016/j.colsurfb.2013.05.001

78. Sekhar CP, Kalidhasan S, Rajesh V, Rajesh N (2009) Bio-polymer adsorbent for the removal of malachite green from aqueous solution. Chemosphere 77(6):842-847. https://doi.org/10.1016/j. chemosphere.2009.07.068

79. Chang F, Xue S, Xie X, Fang W, Fang Z, Xiao Y (2018) Carbohydrate-binding module assisted purification and immobilization of beta-glucosidase onto cellulose and application in hydrolysis of soybean isoflavone glycosides. J Biosci Bioeng 125(2):185-191. https://doi.org/10.1016/j.jbiosc.2017.09.001

80. Kono H, Ogasawara K, Kusumoto R, Oshima K, Hashimoto H, Shimizu Y (2016) Cationic cellulose hydrogels cross-linked by poly(ethylene glycol): Preparation, molecular dynamics, and adsorption of anionic dyes. Carbohyd Polym 152:170-180. https:// doi.org/10.1016/j.carbpol.2016.07.011

81. Saravanan R, Ravikumar L (2016) Cellulose bearing Schiff base and carboxylic acid chelating groups: a low cost and green adsorbent for heavy metal ion removal from aqueous solution. Water science and technology : a journal of the International Association 
on Water Pollution Research 74(8):1780-1792. https://doi.org/10. 2166/wst.2016.296

82. Song T-T, Wang W, Meng L-L, Liu Y, Jia X-B, Mao X (2017) Electrochemical detection of human ferritin based on gold nanorod reporter probe and cotton thread immunoassay device. Chin Chem Lett 28(2):226-230. https://doi.org/10.1016/j.cclet.2016. 07.021

83. Meng LL, Song TT, Mao X (2017) Novel immunochromatographic assay on cotton thread based on carbon nanotubes reporter probe. Talanta 167:379-384. https://doi.org/10.1016/j.talanta.2017.02.023

84. Xun M, Du T-E, Yiyun W, Lili M (2015) Disposable dry-reagent cotton thread-based point-of-care diagnosis device for protein and nucleic acid test. Biosens Bioelectron 65:390-396. https://doi.org/ 10.1016/j.bios.2014.10.053

85. Du T-E, Yiyun W, Yi Z, Tian Z, Xun M (2015) A novel adenosinebased molecular beacon probe for room temperature nucleic acid rapid detection in cotton thread device. Anal Chim Acta 861:69 73. https://doi.org/10.1016/j.aca.2014.12.044

86. Ummartyotin S, Manuspiya H (2015) A critical review on cellulose: From fundamental to an approach on sensor technology. Renew Sust Energ Rev 41:402-412. https://doi.org/10.1016/j. rser.2014.08.050

87. Suhas GVK, Carrott PJ, Singh R, Chaudhary M, Kushwaha S (2016) Cellulose: A review as natural, modified and activated carbon adsorbent. Bioresour Technol 216:1066-1076. https:// doi.org/10.1016/j.biortech.2016.05.106

88. Thakur VK, Thakur MK (2014) Processing and characterization of natural cellulose fibers/thermoset polymer composites. Carbohydr Polym 109:102-117. https://doi.org/10.1016/j. carbpol.2014.03.039

89. Hu W, Chen S, Yang J, Li Z, Wang H (2014) Functionalized bacterial cellulose derivatives and nanocomposites. Carbohydr Polym 101:1043-1060. https://doi.org/10.1016/j.carbpol.2013. 09.102

90. Petersen N, Gatenholm P (2011) Bacterial cellulose-based materials and medical devices: current state and perspectives. Appl Microbiol Biotechnol 91(5):1277-1286. https://doi.org/10.1007/ s00253-011-3432-y

91. Mohite BV, Patil SV (2014) Physical, structural, mechanical and thermal characterization of bacterial cellulose by G. hansenii NCIM 2529. Carbohydr Polym 106:132-141. https://doi.org/10. 1016/j.carbpol.2014.02.012

92. Tang WH, Jia SR, Jia YY, Yang HJ (2009) The influence of fermentation conditions and post-treatment methods on porosity of bacterial cellulose membrane. World J Microbiol Biotechnol 26(1):125-131. https://doi.org/10.1007/s11274-009-0151-y

93. El-Zawahry MM, Abdelghaffar F, Abdelghaffar RA, Hassabo AG (2016) Equilibrium and kinetic models on the adsorption of Reactive Black 5 from aqueous solution using Eichhornia crassipes/chitosan composite. Carbohydr Polym 136:507-515. https://doi.org/10.1016/j.carbpol.2015.09.071

94. Jungmi Lee AASS, Yim Y, Kim S-y, Jeon NL, Min D-H (2019) A FRET assay for the quantitation of inhibitors of exonuclease EcoRV by using parchment paper inkjet-printed with graphene oxide and FAM-labelled DNA. Microchim Acta 186:211-221

95. Deák T, Czigány T (2009) Chemical composition and mechanical properties of basalt and glass fibers: a comparison. Text Res J 79(7):645-651. https://doi.org/10.1177/0040517508095597

96. Hejazi SM, Sheikhzadeh M, Abtahi SM, Zadhoush A (2012) A simple review of soil reinforcement by using natural and synthetic fibers. Constr Build Mater 30:100-116. https://doi.org/10.1016/j. conbuildmat.2011.11.045

97. Velmurugan R, Manikandan V (2007) Mechanical properties of palmyra/glass fiber hybrid composites. Compos A: Appl Sci Manuf 38(10):2216-2226. https://doi.org/10.1016/j.compositesa. 2007.06.006
98. Fridley GE, Holstein CA, Oza SB, Yager P (2013) The evolution of nitrocellulose as a material for bioassays. MRS Bull 38(04): 326-330. https://doi.org/10.1557/mrs.2013.60

99. B Kabariya R, M Ramani V (2018) Exploration of thread for their possible use in fabrication of low cost diagnostic microfluidic device. Mater Sci Res India 15(2):179-184. https://doi.org/10. 13005/msri/150210

100. Nilghaz A, Ballerini DR, Shen W (2013) Exploration of microfluidic devices based on multi-filament threads and textiles: a review. Biomicrofluidic 7(5):0051501-0051516. https://doi. org/10.1063/1.4820413

101. Gong Y, Hu J, Choi JR, You ML, Zheng YM, Xu B, Wen T, Xu F (2017) Improved LFIAs for highly sensitive detection of BNP at point-of-care. Int J Nanomedicine Volume 12:4455-4466. doi: https://doi.org/10.2147/ijn.s135735

102. Tang RH, Yang H, Choi JR, Gong Y, Hu J, Feng SS, PingguanMurphy B, Mei QB, Xu F (2016) Improved sensitivity of lateral flow assay using paper-based sample concentration technique. Talanta 152:269-276. https://doi.org/10.1016/j.talanta.2016.02. 017

103. Rivas L, Medina-Sanchez M, de la Escosura-Muniz A, Merkoci A (2014) Improving sensitivity of gold nanoparticle-based lateral flow assays by using wax-printed pillars as delay barriers of microfluidics. Lab Chip 14(22):4406-4414. https://doi.org/10. 1039/c4lc00972j

104. Lonnberg M, Carlsson J (2001) Quantitative detection in the attomole range for immunochromatographic tests by means of a flatbed scanner. Anal Biochem 293(2):224-231. https://doi.org/ 10.1006/abio.2001.5130

105. Wang Y, Wang L, Zhang C, Liu F (2019) A lateral flow assay for copper(II) utilizing catalytic and stem-loop based signal amplification. Mikrochimica Acta 186(2):82. https://doi.org/10.1007/ s00604-018-3197-4

106. Zhang J, Lv X, Feng W, Li X, Li K, Deng Y (2018) Aptamerbased fluorometric lateral flow assay for creatine kinase MB. Mikrochimica Acta 185(8):364. https://doi.org/10.1007/s00604018-2905-4

107. Hu J, Wang L, Li F, Han YL, Lin M, Lu TJ, Xu F (2013) Oligonucleotide-linked gold nanoparticle aggregates for enhanced sensitivity in lateral flow assays. Lab Chip 13(22):4352-4357. https://doi.org/10.1039/c3lc50672j

108. Araujo AC, Song Y, Lundeberg J, Stahl PL, Brumer H (2012) Activated paper surfaces for the rapid hybridization of DNA through capillary transport. Anal Chem 84(7):3311-3317. https://doi.org/10.1021/ac300025v

109. Misteli T, Zou YP, Mason MG, Wang YL, Wee E, Turni C, Blackall PJ, Trau M, Botella JR (2017) Nucleic acid purification from plants, animals and microbes in under 30 seconds. PLoS Biol 15(11):e2003916. https://doi.org/10.1371/journal.pbio.2003916

110. Kun-Hua Lu J-HL, LIn C-Y, Chen C-F, Yeh Y-C (2019) A fluorometric paper test for chromium(VI) based on the use of N-doped carbon dots. Microchim Acta 186:227-234

111. Shi-jie Li WS, Wen W, Ying G, Wang J-p, Wang S (2018) Three kinds of lateral flow immunochromatographic assays based on the use of nanoparticle labels for fluorometric determination of zearalenone. Microchim Acta 185:238-246

112. Panferov VG, Safenkova IV, Zherdev AV, Dzantiev BB (2018) Post-assay growth of gold nanoparticles as a tool for highly sensitive lateral flow immunoassay. Application to the detection of potato virus X. Mikrochimica Acta 185(11):506. https://doi.org/ 10.1007/s00604-018-3052-7

113. Juanzu Liu JW, Li Z, Meng H, Zhang L, Wang H, Li J, Lingbo Q (2018) A lateral flow assay for the determination of human tetanus antibody in whole blood by using gold nanoparticle labeled tetanus antigen. Microchim Acta 185:110-116 
114. Choi JR, Hu J, Tang R, Gong Y, Feng S, Ren H, Wen T, Li X, Wan Abas WA, Pingguan-Murphy B, Xu F (2016) An integrated paperbased sample-to-answer biosensor for nucleic acid testing at the point of care. Lab Chip 16(3):611-621. https://doi.org/10.1039/ $\mathrm{c} 51 \mathrm{c} 01388 \mathrm{~g}$

115. Jones S, Sutherland CJ, Hermsen C, Arens T, Teelen K, Hallett R, Corran P, van der Vegte-Bolmer M, Sauerwein R, Drakeley CJ, Bousema T (2012) Filter paper collection of Plasmodium falciparum mRNA for detecting low-density gametocytes. Malar J 11:266-275. doi:https://doi.org/10.1186/1475-2875-11-266

116. Dusek RJ, Hall JS, Nashold SW, TeSlaa JL, Ip HS (2011) Evaluation of Nobuto filter paper strips for the detection of avian Antibody in Waterfowl. Avian Dis 55:674-676. https://doi.org/10. 1637/9687-021511-ResNote.1

117. Pritsch M, Wieser A, Soederstroem V, Poluda D, Eshetu T, Hoelscher M, Schubert S, Shock J, Loescher T, Berens-Riha N (2012) Stability of gametocyte-specific Pfs25-mRNA in dried blood spots on filter paper subjected to different storage conditions. Malar J 11:138-144. https://doi.org/10.1186/1475-2875-11138

118. Metherel AH, Aristizabal Henao JJ, Stark KD (2013) EPA and DHA levels in whole blood decrease more rapidly when stored at -20 degrees $\mathrm{C}$ as compared with room temperature, 4 and -75 degrees C. Lipids 48(11):1079-1091. https://doi.org/10.1007/ s11745-013-3827-x

119. Ulum MF, Maylina L, Noviana D, Wicaksono DH (2016) EDTAtreated cotton-thread microfluidic device used for one-step whole blood plasma separation and assay. Lab Chip 16(8):1492-1504. https://doi.org/10.1039/c6lc00175k

120. Kraus RH, van Hooft P, Waldenstrom J, Latorre-Margalef N, Ydenberg RC, Prins HH (2011) Avian influenza surveillance with FTA cards: field methods, biosafety, and transportation issues solved. Jove-J Vis Exp (54). https://doi.org/10.3791/2832

121. Maignan M, Viglino D, Hablot M, Termoz Masson N, Lebeugle A, Collomb Muret R, Mabiala Makele P, Guglielmetti V, Morand P, Lupo J, Forget V, Landelle C, Larrat S (2019) Diagnostic accuracy of a rapid RT-PCR assay for point-of-care detection of influenza $\mathrm{A} / \mathrm{B}$ virus at emergency department admission: a prospective evaluation during the 2017/2018 influenza season. PLoS One 14(5):e0216308. https://doi.org/10.1371/journal.pone.0216308

122. Yang C-H, Chen C-A, Chen C-F (2018) Surface-modified cellulose paper and its application in infectious disease diagnosis. Sensors Actuators B Chem 265:506-513. https://doi.org/10. 1016/j.snb.2018.03.092

123. Zhang H, Lei Z, Tian R, Wang Z (2018) Polyamidoamine starburst dendrimer-activated chromatography paper-based assay for sensitive detection of telomerase activity. Talanta 178:116-121. https:// doi.org/10.1016/j.talanta.2017.09.034

124. Moazeni M, Karimzadeh F, Kermanpur A (2018) Peptide modified paper based impedimetric immunoassay with nanocomposite electrodes as a point-of-care testing of Alpha-fetoprotein in human serum. Biosens Bioelectron 117:748-757. https://doi.org/10.1016/ j.bios.2018.07.016

125. Chan SK, Lim TS (2016) A straw-housed paper-based colorimetric antibody-antigen sensor. Anal Methods 8(6):1431-1436. https://doi.org/10.1039/c5ay01828e

126. Wang S, Ge L, Song X, Yu J, Ge S, Huang J, Zeng F (2012) Paperbased chemiluminescence ELISA: lab-on-paper based on chitosan modified paper device and wax-screen-printing. Biosens Bioelectron 31(1):212-218. https://doi.org/10.1016/j.bios.2011. 10.019

127. Li W, Ge S, Wang S, Yan M, Ge L, Yu J (2013) Highly sensitive chemiluminescence immunoassay on chitosan membrane modified paper platform using $\mathrm{TiO} 2$ nanoparticles/multiwalled carbon nanotubes as label. Luminescence 28(4):496-502. https://doi.org/ 10.1002/bio. 2482
128. Marín-Barroso E, Moreira CM, Messina GA, Bertolino FA, Alderete M, Soler-Illia GJAA, Raba J, Pereira SV (2018) Paper based analytical device modified with nanoporous material for the fluorescent sensing of gliadin content in different food samples. Microchem J 142:78-84. https://doi.org/10.1016/j.microc.2018. 06.005

129. Choi JR, Nilghaz A, Chen L, Chou KC, Lu X (2018) Modification of thread-based microfluidic device with polysiloxanes for the development of a sensitive and selective immunoassay. Sensors Actuators B Chem 260:1043-1051. https://doi.org/10.1016/j.snb. 2018.01.102

130. Preechakasedkit P, Siangproh W, Khongchareonporn N, Ngamrojanavanich N, Chailapakul O (2018) Development of an automated wax-printed paper-based lateral flow device for alphafetoprotein enzyme-linked immunosorbent assay. Biosens Bioelectron 102:27-32. https://doi.org/10.1016/j.bios.2017.10. 051

131. Lu JJ, Ge SG, Ge L, Yan M, Yu JH (2012) Electrochemical DNA sensor based on three-dimensional folding paper device for specific and sensitive point-of-care testing. Electrochim Acta 80:334 341. https://doi.org/10.1016/j.electacta.2012.07.024

132. Gomes HI, Sales MG (2015) Development of paper-based color test-strip for drug detection in aquatic environment: Application to oxytetracycline. Biosens Bioelectron 65:54-61. https://doi.org/10. 1016/j.bios.2014.10.006

133. Wang Y, Luo J, Liu J, Li X, Kong Z, Jin H, Cai X (2018) Electrochemical integrated paper-based immunosensor modified with multi-walled carbon nanotubes nanocomposites for point-ofcare testing of 17beta-estradiol. Biosens Bioelectron 107:47-53. https://doi.org/10.1016/j.bios.2018.02.012

134. Devadhasan JP, Kim J (2018) A chemically functionalized paperbased microfluidic platform for multiplex heavy metal detection. Sensors Actuators B Chem 273:18-24. https://doi.org/10.1016/j. snb.2018.06.005

135. Cao R, Zhang X, Tan W, Shen W (2018) Precipitation assay meets low wettability on paper: a simple approach for fabricating patterned paper sensors. Cellulose 25(1):583-592. https://doi.org/10. 1007/s10570-017-1551-z

136. Chaiyo S, Mehmeti E, Siangproh W, Hoang TL, Nguyen HP, Chailapakul O, Kalcher K (2018) Non-enzymatic electrochemical detection of glucose with a disposable paper-based sensor using a cobalt phthalocyanine-ionic liquid-graphene composite. Biosens Bioelectron 102:113-120. https://doi.org/10.1016/j.bios.2017.11. 015

137. Salekin S, Bari MG, Raphael I, Forsthuber TG, Zhang JM (2017) Early disease correlated protein detection using early response index (ERI). BMC Bioinformatics 18:313-324

138. Shafiee H, Asghar W, Inci F, Yuksekkaya M, Jahangir M, Zhang MH, Durmus NG, Gurkan UA, Kuritzkes DR, Demirci U (2015) Paper and flexible substrates as materials for biosensing platforms to detect multiple biotargets. Sci Rep 5:8719. https://doi.org/10. 1038/srep08719

139. Liu Z, Hu J, Li A, Feng SS, Qu ZG, Xu F (2017) The effect of report particle properties on lateral flow assays: A mathematical model. Sensors Actuators B Chem 248:699-707. https://doi.org/ 10.1016/j.snb.2017.04.024

140. Liu Z, Hu J, Zhao YM, Qu ZG, Xu F (2015) Experimental and numerical studies on liquid wicking into filter papers for paperbased diagnostics. Appl Therm Eng 88:280-287. https://doi.org/ 10.1016/j.applthermaleng.2014.09.057

141. Wang W, Liang T, Bai H, Dong W, Liu X (2018) All cellulose composites based on cellulose diacetate and nanofibrillated cellulose prepared by alkali treatment. Carbohydr Polym 179:297-304. https://doi.org/10.1016/j.carbpol.2017.09.098

142. Natalio D, Fuchs R, Cohen SR, Leitus G, Fritz-Popovski G, Paris O, Kappi M, Butt H-J (2017) Biological fabrication of cellulose 
fibers with tailored properties. Science 357:1118-1122. https:// doi.org/10.1126/science.aan5830

143. Lee CH, Chuang WY, Cowan MA, Wu WJ, Lin CT (2014) A lowpower integrated humidity CMOS sensor by printing-on-chip technology. Sensors 14(5):9247-9255. https://doi.org/10.3390/ s140509247

144. Bhakta SA, Borba R, Taba M, Jr., Garcia CD, Carrilho E (2014) Determination of nitrite in saliva using microfluidic paper-based analytical devices. Anal Chim Acta 809:117-122. doi:https://doi. org/10.1016/j.aca.2013.11.044

145. Cate DM, Dungchai W, Cunningham JC, Volckens J, Henry CS (2013) Simple, distance-based measurement for paper analytical devices. Lab Chip 13(12):2397-2404. https://doi.org/10.1039/ c3lc50072a

146. Rahman Bhuiyan MA, Hossain MA, Zakaria M, Islam MN, Zulhash Uddin M (2016) Chitosan Coated Cotton Fiber: Physical and Antimicrobial Properties for Apparel Use. J Polym
Environ 25(2):334-342. https://doi.org/10.1007/s10924-0160815-2

147. Son SU, Seo SB, Jang S, Choi J, J-w L, Lee DK, Kim H, Seo S, Kang T, Jung J, Lim E-K (2019) Naked-eye detection of pandemic influenza a ( $\mathrm{pH} 1 \mathrm{~N} 1)$ virus by polydiacetylene (PDA)-based paper sensor as a point-of-care diagnostic platform. Sensors Actuators B Chem 291:257-265. https://doi.org/10.1016/j.snb.2019.04.081

148. Fan Y, Shi S, Ma J, Guo Y (2019) A paper-based electrochemical immunosensor with reduced graphene oxide/thionine/gold nanoparticles nanocomposites modification for the detection of cancer antigen 125. Biosens Bioelectron 135:1-7. https://doi.org/10. 1016/j.bios.2019.03.063

Publisher's note Springer Nature remains neutral with regard to jurisdictional claims in published maps and institutional affiliations. 